\title{
SEQUÍAS Y GOLPES DE CALOR EN EL SURESTE IBÉRICO: EFECTOS TERRITORIALES Y ECONÓMICOS
}

\author{
Jorge Olcina Cantos \\ Antonio Rico Amorós
}

\begin{abstract}
«Desgraciadamente las lluvias son allí irregulares, sin período, vienen de tarde en tarde, por cuya sequía tan continuada se hallan aquellos inmensos campos, que se llaman de secano, casi siempre sin cultivo»

D. José de Echegaray

Memoria sobre las causas de la sequía en las provincias de Almería y Murcia
\end{abstract}

\section{RESUMEN}

Las secuencias de sequía, evento atmosférico propio de las tierras del sureste ibérico por su filiación subtropical, se constituyen en el riesgo climático que ocasiona más pérdidas económicas en la actividad agraria de este sector peninsular. Además, sus consecuencias suelen verse acrecentadas al coincidir con el desarrollo de «golpes de calor» que perjudican igualmente las cosechas. El análisis de las causas atmosféricas y de los efectos económicos y territoriales de ambos fenómenos meteorológicos son aspectos que aborda el prsente escrito.

Palabras clave: sequía, golpes de calor, pérdidas económicas, escasez de recursos hídricos, consecuencias medioambientales.

\begin{abstract}
The sequences of drought, a characterictic atmospheric event of the southeast iberian lands due to its subtropical relation, constitute the climatic risk which produces the mayority of economic losses in the agrarian activity of this peninsular area. Besides its consequences increase with the development of «heat waves» with damage equally the crops. The analysis of the atmospheric causes ant the economic ant territorial effects of these meteorological phenomena are aspects which this paper breachs.
\end{abstract}

Key words: drought, «heat waves», economical losses, scarcity of hydrical resources, enviromental consequences. 


\section{Introducción}

Al iniciar la redacción del presente escrito ha concluido uno de los años hidrológicos más secos (1993/94) y uno de los estíos con más jornadas de calor bochornoso de la presente centuria, fenómenos que han provocado graves pérdidas económicas en la actividad agraria del sureste de la Península Ibérica, aquejadas de natural carencia de recursos pluviométricos. La mengua de recursos hídricos ocasionada por esta aguda reducción de lluvias ha avivado, además, los conflictos regionales por el disfrute del agua, comprensiblemente exagerados al calor de las expectativas de aprobación del Plan Hidrológico Nacional.

Las consecuencias de esta indigencia pluviométrica unidas a una inusitada sucesión de «golpes de calor» y desorbitados registros de temperatura máximas que han tenido lugar en la presente temporada estival han sido, por su parte, deliberadamente desmesuradas en los medios de comunicación que han obtenido indicios suficientes para justificar las ideas del «cambio climático» o los efectos del agujero de ozono sobre la radiación solar recibida; en definitiva, para argumentar el supuesto proceso de desertización en que estarían inmersas buena parte de las tierras del cuadrante sureste de la Península Ibérica. La divulgación científica mal entendida (vulgarización) llevada a cabo por los medios de masas ha contribuido a consolidar en la opinión pública el atrayente pero erroneo axioma siguiente: SEQUÍA $\rightarrow$ CAMBIO CLIMÁTICO $\longrightarrow$ INCREMENTO DE TEMPERATURAS $\rightarrow$ AUMENTO DE INCENDIOS FORESTALES—D DESERTIZACIÓN.

Parece oportuno, pues, realizar, con visión geográfica, una reflexión pausada sobre las causas y efectos de las sequías y golpes de calor en la región del sureste peninsular dos aspectos climáticos, a menudo tenidos por equivalentes, que aúnan esfuerzos para incrementar la sensación de escasez de lluvias y sequedad ambiental propias de su realidad climática. El catálogo de repercusiones de estos dos aspectos debe incluir evaluación precisa de las pérdidas de cosecha, análisis de las respuestas de los sistemas de captación y distribución de agua para abastecimiento agrario y urbano y, asimismo, el estudio de las consecuencias de la escasez de lluvias sobre el medio ambiente (incendios forestales, humedales y, en última instancia, los recursos cinegéticos).

\section{Aspectos climáticos asociados a sequías y golpes de calor en el sureste ibérico}

Sequías y golpes de calor son dos fenónemos meteorológicos propios de la realidad climática de las tierras peninsulares que, por propia ubicación geográfica, son partícipes, con elevada frecuencia, de dinámicas de circulación atmosférica subtropicales. Porque, en efecto, aunque ambos fenómenos poseen duración temporal y efectos económicos y medioambientales diversos, muestran, empero, una estrecha relación genética puesto que su desarrollo sobre las tierras peninsulares se asocia a la presencia de estas circulaciones atmosféricas de raigambre subtropical. En unos casos, como jornadas puntuales de calor ahornagante, en otros como secuencias de larga duración que implican cambios en diversos elementos climáticos entre los que sobresale, como más perjudicial, la ausencia prolongada de lluvias.

Dos aspectos relacionan, por tanto, a estos dos fenómenos atmosféricos: Por un lado, sequías y golpes de calor disfrutan de idéntico origen sinóptico y, por otro, los episodios de «ola de calor» muestran preferencia de desarrollo en el verano de los años de indigencia pluviométrica sin que ello suponga que golpes de calor puedan generarse, por su propio carácter de episodio puntual, en el seno de años de normalidad o abundancia de lluvias. Respecto al origen de estos dos fenómenos cuatro son, como muestra el grafico $\mathrm{n}^{\circ} 1$, las 


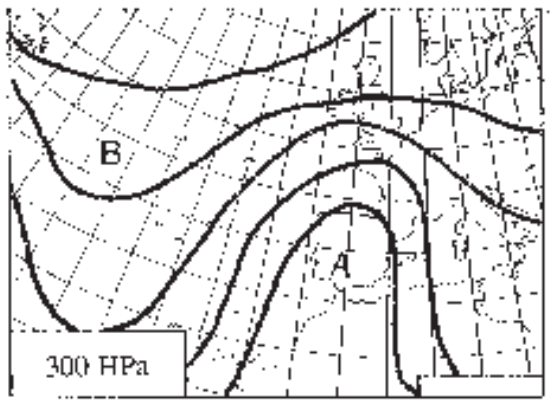

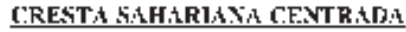

- Milit de uje tropicul oontineutul.

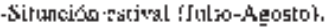

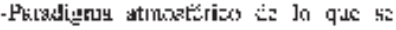

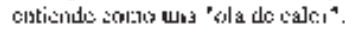

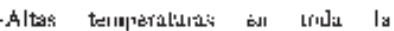

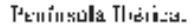

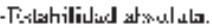

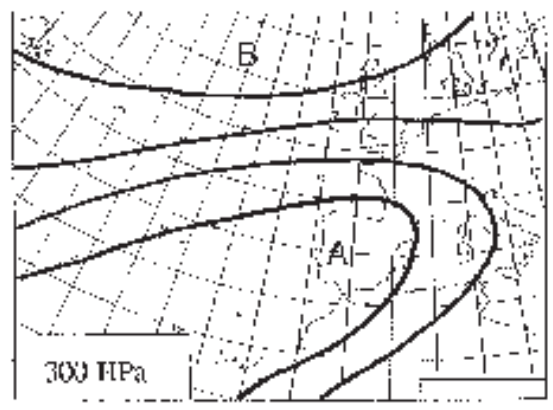

DPRS.AL TROTHITMT.

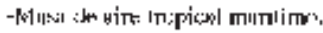

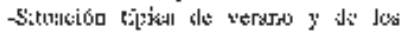

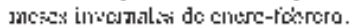

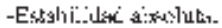

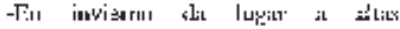

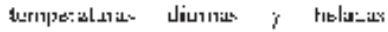
Ji il:LLu rili--

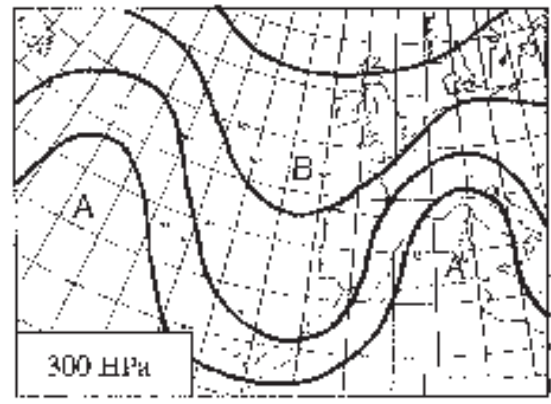

CRESTA SAULALAN THFTITF.RRANEA

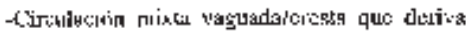

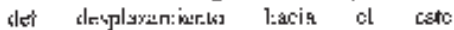

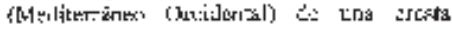

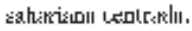

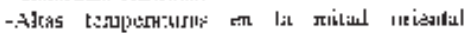

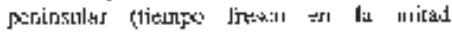
a-cidant:

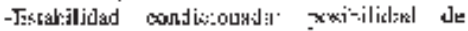

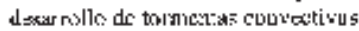

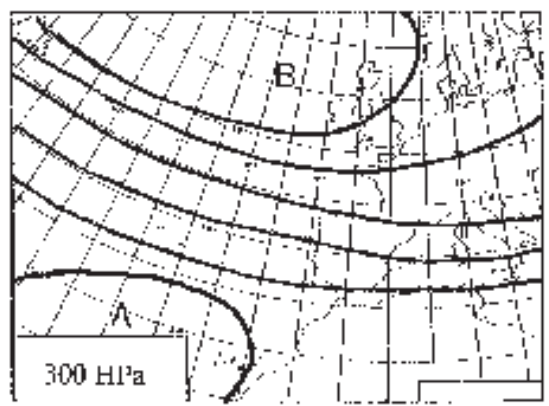

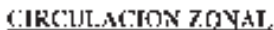

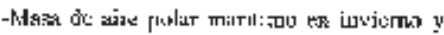

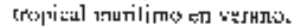

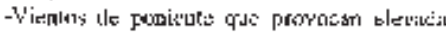

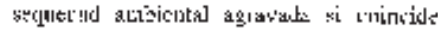

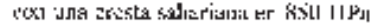

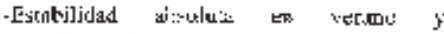

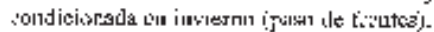

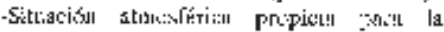

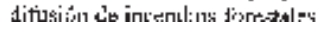

GRÁFICO N ${ }^{\circ} 1$

circulaciones atmosféricas que originan golpes de calor y cuando persisten en el tiempo, sequías:

1) Cresta sahariana centrada o advección de aire sahariano que dibuja una enérgica loma planetaria con su eje en torno a $5^{\circ}$ oeste, de manera que las condiciones anticiclónicas abrazan la totalidad de las tierras peninsulares. Es la situación sinóptica tenida por 
paradigma de lo que se entiende como «golpe de calor». En la alta troposfera, la altitud de estas lomas y los caracteres térmicos de la masa de aire tropical vehiculada hacia la Península Ibérica varía entre $9.360 \mathrm{~m}$. y $9.720 \mathrm{~m}$. según el mes del año en que se presentan.

2) Cresta sahariana mediterránea o advección de aire sahariano que afecta a la mitad oriental de la Península Ibérica y cuenca del Mediterráneo Occidental. Esta situación deriva de la anterior por el desplazamiento hacia el este de crestas saharianas centradas en relación con la aproximación por el Atlántico de vaguadas de aire polar marítimo. Se establece, de este modo, una situación atmosférica con circulación mixta (Vaguada-Cresta) que determina la aparición de tiempo diferenciados en las mitades occidental y oriental de la Península. En esta última dominan los rasgos propios de la advección subtropical que impone altas temperaturas y sequedad ambiental.

3) Dorsal subtropical marítima, que supone la instalación en el espacio sinóptico peninsular de una estructura anticiclónica, con eje orientado de suroeste (Atlántico norte subtropical) a noreste (Europa central) que supone la instalación de la masa de aire tropical marítima en nuestras latitudes. Esta situación impone subsidencia anticiclónica y, por ende, ausencia total de precipitaciones. Las dorsales subtropicales muestran preferencia de aparición en verano y en los meses centrales del invierno (enero-febrero); en este último caso su presencia condiciona el registro de altas temperaturas diurnas y fuertes descensos térmicos por la noche con génesis de heladas.

4) Circulaciones zonales. Las circulaciones del oeste, paradigma de la dinámica atmosférica de latitudes medias (paso de borrascas del frente polar y precipitaciones) suponen persistencia de las condiciones de sequedad ambiental y altas temperaturas en el sureste de la Península Ibérica al ser afectado por vientos catabáticos tras su tránsito por las tierras meseteñas. De manera que la inestabilidad asociada a la instalación de una circulación zonal deviene, en nuestro ámbito, en condiciones barotrópicas con ausencia de lluvias (si no median superficies frontales muy enérgicas), vientos de moderada velocidad y súbito incremento de los registros térmicos y de la evaporación. Cuando acontecen en los meses centrales del verano se acompañan, junto al súbito incremento de las temperaturas, de un extraordinario poder desecande del aire en circulación por efecto foëhn con efectos abrasadores sobre cultivos y personas. Son las conocidas «ponentadas».

La aparición puntual de uno u otro tipo circulatorio a lo largo de la temporada estival condiciona pues, el desarrollo de advecciones de aire muy cálido y seco con efectos inmediatos de ascenso térmico desorbitado y mengua exagerada de los valores de humedad. La permanencia de estas circulaciones de origen subtropical a lo largo del curso anuo origina, por su parte, un importante descenso de los volúmenes de lluvia recogidos (se-

\section{Cuadro 1}

$N^{\circ}$ DE JORNADAS CON SITUACIONES ATMOSFÉRICAS POCO PROCLIVES AL DESARROLLO DE LLUVIAS DURANTE LOS AÑOS SECOS 1981, 1983, 1993 Y 1994

\begin{tabular}{|lcccc|}
\hline SITUACIÓN ATMOSFÉRICA & $\mathbf{1 9 8 1}$ & $\mathbf{1 9 8 3}$ & $\mathbf{1 9 9 3}$ & $\mathbf{1 9 9 4}$ \\
\hline DORSALES DE AIRE SUBTROPICAL & $\begin{array}{c}150 \\
56\end{array}$ & $\begin{array}{c}174 \\
33\end{array}$ & $\begin{array}{c}131 \\
33\end{array}$ & $\begin{array}{c}118 \\
35\end{array}$ \\
\hline CIRCULACIONES ZONALES & 206 & 207 & 164 & 153 \\
\hline TOTAL & 207 &
\end{tabular}

* hasta septiembre.

Fuente: Boletín Meteorológico Diario. Instituto Nacional de Meteorología. 
quía). El cuadro adjunto $\mathrm{n}^{\circ} 1$ muestra el número de jornadas con dinámica atmosférica poco proclive para la génesis de precipitaciones en el sureste ibérico registradas en los años secos 1981, 1983, 1993 y 1994. Recordemos que el número medio de días con lluvia en los observatorios de este ámbito peninsular apenas alcanza los 50 que se ven reducidos a la mitad en años de indigencia pluviométrica.

Por otra parte, como se ha señalado, los golpes de calor muestran querencia de desarrollo en los veranos de años de indigencia pluviométrica; aspecto, por lo demás, comprensible si tenemos en cuenta el predominio de las circulaciones atmosféricas de raigambre subtropical señaladas a lo largo de un año seco (vid. cuadro $\mathrm{n}^{\circ} 2$ ). Ahora bien, como se indica a continuación, ello no quiere decir que la temporada estival de un año seco sea más cálida respecto a años de normalidad o abundancia pluviométrica. Antes al contrario, los meses centrales de verano (julio-septiembre) de un año seco se caracterizan, paradojicamente, por disfrutar de registros térmicos máximo y mínimos de valor más menguado que en años de lluviosos (vid. infra).

Junto a estos aspectos comunes a ambos fenómenos atmosféricos, golpes de calor y sequías disfrutan de rasgos atmosféricos que imprimen peculiaridad a cada uno de ellos y, por tanto, merecen destacarse. Así, los golpes de calor son, como se ha señalado, pulsaciones atmosféricas de corta duración (2-3 días) que disparan los registros térmicos máximos reduciendo, al mismo tiempo, de forma acusada, los registros de humedad relativa (vid. cuadro $\mathrm{n}^{\mathrm{o}} 3$ ). Son éstas situaciones atmosféricas de aparición preferentemente estival, aunque no son exclusivas de esta estación del año porque, en efecto, golpes de calor pueden acontecer en meses equinocciales o incluso en meses invernales (febrero) a favor de la instalación de dorsales subtropicales sobre el espacio sinóptico peninsular que ocasionan cambios bruscos en el tiempo diario percibidos de modo más acusado, si cabe, que en las propias pulsaciones ocurridas en los meses de verano. No obstante, los registros

Cuadro 2

RELACIÓN ENTRE GOLPES DE CALOR Y SECUENCIAS DE SEQUÍA EN EL SURESTE IBÉRICO

\begin{tabular}{|cc|}
\hline Golpes de calor & $\begin{array}{c}\text { Características pluviométricas } \\
\text { del año en que tiene lugar }\end{array}$ \\
\hline $16-$ V-1961 & Año muy seco \\
12 -VII-1961 & Año muy seco \\
20 a $23-$ VII-1967 & Año de normalidad pluviométrica \\
14 y 15-VIII-1969 & Año húmedo \\
31 -VII a 5-VIII-1971 & Año muy húmedo \\
14 y 15-VII-1975 & Año de normalidad pluviométrica \\
16 y 18-VII-1978 & Año seco \\
13-VI-1981 $22-$ III-1980 & Año de normalidad pluviométrica \\
7-VII-1982 & Secuencia de sequía 1981-84 \\
11-VI-1983 & Secuencia de sequía 1981-84 \\
6-VII-1984 & Secuencia de sequía 1981-84 \\
4-VII-1996 & Secuencia de sequía 1981-84 \\
& Año de normalidad pluviométrica \\
\end{tabular}

Fuente: Valero Amat. Op. cit. bibliografía (modificado). Elaboración propia. 
Cuadro 3

SITUACIONES ATMOSFÉRICAS CAUSANTES DE GOLPES DE CALOR Y REGISTROS TÉRMICOS MÁXIMO ALCANZADOS EN DIVERSOS OBSERVATORIOS

DEL SURESTE IBÉRICO

\begin{tabular}{|c|c|c|}
\hline Golpes de calor & Situación atmosférica & $\mathrm{T}^{\mathrm{a}}$ máxima absoluta \\
\hline $15-V-1961$ & $\begin{array}{c}\text { Dorsal de aire Tropical marítimo en } \\
500 \mathrm{HPa} \\
\text { Advección sahariana en } 850 \mathrm{HPa}\end{array}$ & $\begin{array}{c}\text { Orihuela } 30^{\circ} \mathrm{C} \\
\text { Murcia } 37^{\circ} \mathrm{C} \\
\text { Alicante } 33,4^{\circ} \mathrm{C}\end{array}$ \\
\hline 12-VII-1961 & $\begin{array}{l}\text { Depresión Británica muy } \\
\text { intensa. Circulación zonal del NW } \\
\text { «Galerna» en el Cantábrico }\end{array}$ & $\begin{array}{c}\text { Elche } 41,5^{\circ} \mathrm{C} \\
\text { Murcia } 41^{\circ} \mathrm{C} \\
\text { (2\% hum. rel. a } 13 \mathrm{~h} .) \\
\text { Alicante } 41,2^{\circ} \mathrm{C}\end{array}$ \\
\hline 20 a $23-$ VII- 1967 & Cresta sahariana mediterránea & $\begin{array}{l}\text { Novelda y Villena } 42^{\circ} \mathrm{C} \\
\text { Alcantarilla } 44^{\circ} \mathrm{C} \\
\text { Alicante } 39,8^{\circ} \mathrm{C}\end{array}$ \\
\hline 14 y $15-$ VIII-1969 & Cresta sahariana mediterránea & $\begin{array}{l}\text { Novelda } 41^{\circ} \mathrm{C} \\
\text { Murcia } 40^{\circ} \mathrm{C} \\
\text { Alicante } 39,2^{\circ} \mathrm{C}\end{array}$ \\
\hline 31-VII-1971 & Cresta sahariana mediterránea & $\begin{array}{c}\text { Elche y Orihuela } 41^{\circ} \mathrm{C} \\
\text { Murcia } 42^{\circ} \mathrm{C} \\
\text { Alicante } 38,3^{\circ} \mathrm{C}\end{array}$ \\
\hline 14 y $15-$ VII- 1975 & Cresta sahariana mediterránea & $\begin{array}{c}\text { Orihuela } 42^{\circ} \mathrm{C} \\
\text { Murcia } 41^{\circ} \mathrm{C} \\
\text { Alicante } 37,4^{\circ} \mathrm{C}\end{array}$ \\
\hline 16 у 18 -VII-1978 & Cresta sahariana centrada & $\begin{array}{l}\text { Villena } 45^{\circ} \mathrm{C} \\
\text { Doña Inés } 48^{\circ} \mathrm{C} \\
\text { Alicante } 36,4^{\circ} \mathrm{C}\end{array}$ \\
\hline 22-VII-1980 & Cresta sahariana centrada & $\begin{array}{c}\text { Villena } 43^{\circ} \mathrm{C} \\
\text { Murcia } 42^{\circ} \mathrm{C} \\
\text { Alicante } 36,6^{\circ} \mathrm{C}\end{array}$ \\
\hline 13-VI-1981 & Cresta sahariana centrada & $\begin{array}{l}\text { Villena } 38^{\circ} \mathrm{C} \\
\text { Alicante } 31^{\circ} \mathrm{C}\end{array}$ \\
\hline 7-VII-1982 & Cesta sahariana centrada & $\begin{array}{l}\text { Orihuela } 42^{\circ} \mathrm{C} \\
\text { Murcia } 43^{\circ} \mathrm{C} \\
\text { Alicante } 35^{\circ} \mathrm{C}\end{array}$ \\
\hline 11-VI-1983 & Cresta sahariana centrada & $\begin{array}{c}\text { Villena } 41^{\circ} \mathrm{C} \\
\text { Alicante } 31,8^{\circ} \mathrm{C}\end{array}$ \\
\hline 24-VII-1984 & Cresta sahariana centrada & $\begin{array}{c}\text { Villena } 44^{\circ} \mathrm{C} \\
\text { Murcia } 44^{\circ} \mathrm{C} \\
\text { Alicante } 38,2^{\circ} \mathrm{C}\end{array}$ \\
\hline 6-VII-1986 & $\begin{array}{l}\text { Circulación zonal del NW } \\
\text { Cresta sahariana en } 850 \mathrm{HPa}\end{array}$ & $\begin{array}{c}\text { Monforte Cid } 44,6^{\circ} \mathrm{C} \\
\text { Murcia } 42^{\circ} \mathrm{C} \\
\text { Alicante } 37,4^{\circ} \mathrm{C}\end{array}$ \\
\hline 4-VII-1994 & Cresta sahariana mediterránea & $\begin{array}{c}\text { S. Miguel Salinas } 46^{\circ} \mathrm{C} \\
\text { Murcia } 46^{\circ} \mathrm{C} \\
\text { Alicante } 41,4^{\circ} \mathrm{C}\end{array}$ \\
\hline
\end{tabular}

Fuente: Boletín Meteorológico Diario (I.N.M.). Centro Meteorológico Zonal de Valencia-Viveros. Elaboración propia. 


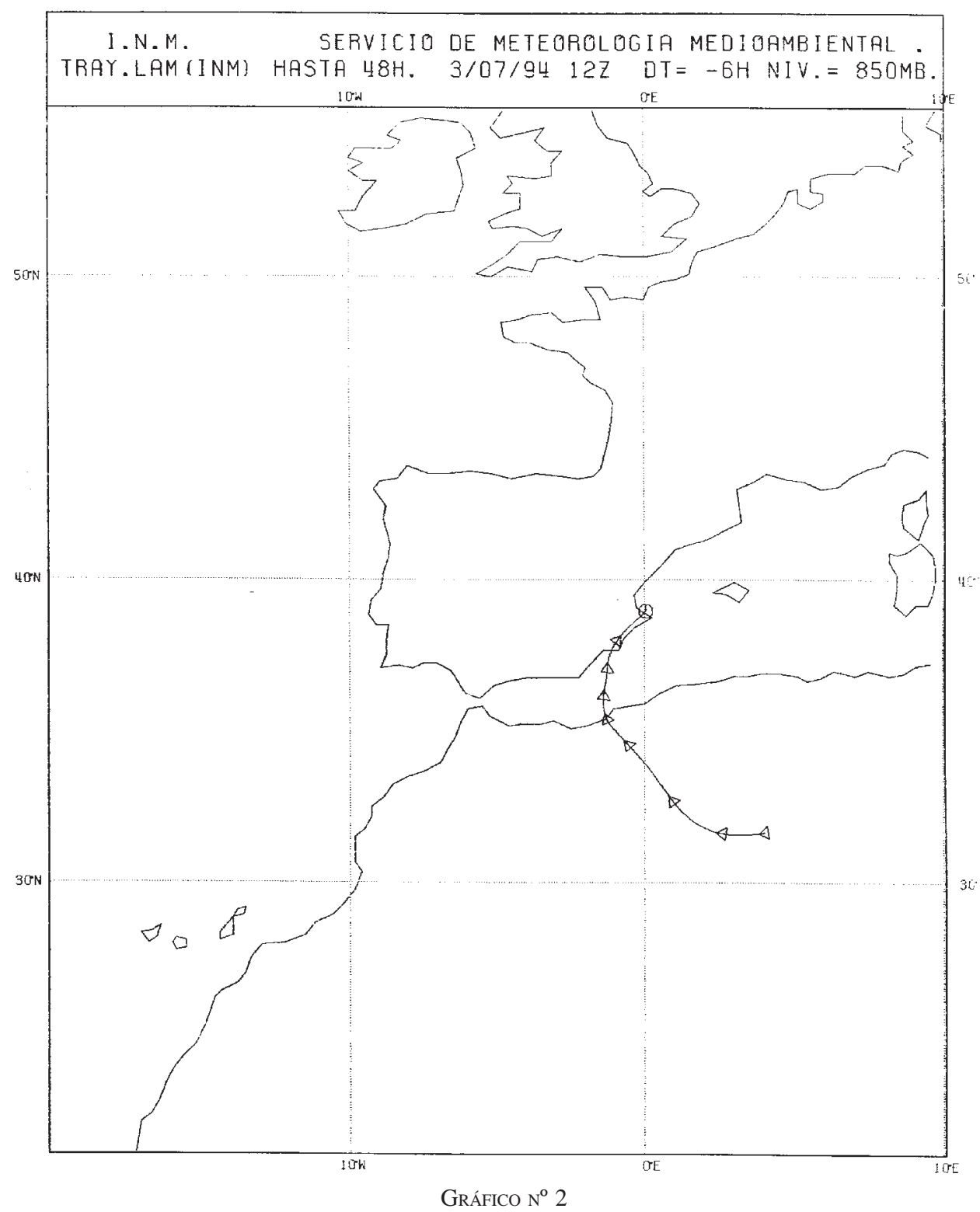

«record» de temperatura máxima se asocian con los golpes de calor de los meses caniculares del verano que condicionan el registro de valores térmicos diurnos próximos a $40^{\circ} \mathrm{C} \mathrm{e}$ incluso superiores como ocurre en la propia huerta de Murcia o en la totalidad de tierras interiores del sureste ibérico. Por su parte, en las jornadas centrales de estos episodios, los valores de humedad relativa a mediodía no suelen rebasar el $50 \%$ en la franja costera o el $30 \%$ en las tierras del interior, no siendo desconocidos registros inferiores a 10\%. (vid. cuadro $\mathrm{n}^{\mathrm{o}} 3$ ). 
Sinópticamente, junto a la instalación, sobre las tierras peninsulares, de una de las cuatro situaciónes atmosféricas señaladas con anterioridad, los golpes de calor que afectan a las tierras del suereste ibérico vienen caracterizados por la instalación de isotermas anormalmente elevadas a lo largo de la columna atmosférica. Así, en $850 \mathrm{Hpa}^{1}$, las invasiones de aire subtropical que acontecen en los meses centrales de verano sitúan isotermas de $24^{\circ}$ ó $28^{\circ}$ sobre la mitad sur de la Península. La retrotrayectoria a $850 \mathrm{Hpa}$ del 3 de julio de 1994 (vid. gráfico ${ }^{\circ}$ 2) muestra un ejemplo paradigmático de pulsación muy cálida asociada a la llegada de la masa de aire sahariana a las tierras peninsulares que situó la isoterma de $28^{\circ} \mathrm{C}$ de sobre la vertical del cuadrante sureste peninsular $(1.560 \mathrm{~m})$.

La frecuencia de aparición de estas pulsaciones cálidas no suele rebasar un episodio al año. No obstante, y en el marco de un años muy secos, no es extraño el desarrollo de dos o tres «golpes de calor» sobre las tierras del sureste ibérico. Es el caso de las secuencias de calor intenso ocurridas en 1961 o las más reciente del verano de 1994 que ha concentrado tres episodios de calor en los meses de julio y agosto (primera y última semana de julio y 9 y 10 de agosto) con su corolario de génesis de incendios forestales en toda la fachada mediterránea peninsular (vid. infra, apartado ${ }^{\circ} 3$ ).

Más complejos son, por su parte, los efectos de secuencias de sequía sobre el resto de elementos del clima. Así, una primera cuestión atañe a la propia definición climática de «sequía». Variada es la gama de definiciones del concepto de sequía, si bien ninguna disfruta de carácter universal. Desechables, atendiendo a los caracteres del ritmo pluviométrico de nuestro ámbito de estudio, resultan las propuestas de Cole que denomina sequía la período de 15 días sin lluvia o de la British Rainfall Organization que define la sequía absoluta como el intervalo de 15 días consecutivos en el que no se recogen mas de 0,25 mm. de lluvia en ninguno de ellos. Esta condición, rasgo condigno al verano de la fachada mediterránea peninsular, no se cumple ni en la estación meteorológica que mayor volumen anual de lluvia concentra de todo el cuadrante sureste peninsular (Pego), donde incluso en años considerados de abundancia pluviométrica suelen transcurrir un mes, e incluso dos, sin llover (es el caso del mes de julio de 1972, año con una cantidad total de lluvia de $1.183,3 \mathrm{~mm}$. o de los meses de julio, agosto y primera década de septiembre del año 1971, que acumuló un volumen total de $1.137 \mathrm{~mm}$.). Más ajustada es la definición propuesta por Baldwin-Wiseman que entiende la sequía como el intervalo de 3 meses o más - sin precisar - con una precipitación inferior al $50 \%$ de la media normal ${ }^{2}$. Recientemente, la Organización Meteorológica Mundial, a petición del Programa de las Naciones Unidas para el Desarrollo e inserto en su estudio sobre los efectos de la secuencia seca de 1974$1985^{3}$, propuso definir la sequía como la secuencia atmosférica caracterizada por el desarrollo de precipitaciones inferiores un $60 \%$ a las normales durante más de dos años consecutivos.

De entrada, resulta necesario matizar entre año seco, curso anual con volúmenes de precipitación total inferiores a la media normal de una determinada estación meteorológica desarrollado entre años con precipitaciones normales o superiores a la cantidad media de una serie de, al menos, 30 años, y secuencia de ingencia pluviométrica (sequía), de mayor

1 El análisis de esta superficie topográfica resulta particularmente idóneo para el estudio de las invasiones de aire sahariano merced al nítido trazado que muestran, en dichas jornadas, las líneas isotermas en su avance hacia las tierras ibéricas.

2 Vid. SÁNCHEZ MUNIOSGUREN, L.: «Definición de sequía. Clima y Sequía. La predicción de sequías. Sequías en la Península Ibérica» en Jornadas sobre Las Sequías en España. Real Academia de Ciencias Exactas, Físicas y Naturales. Madrid, Noviembre de 1990, pp. 11-30.

3 Vid. O.M.M.: Report on drought and countries affected by drought during 1974-85. Ginebra, 1986. 
duración y que deviene de la agudización de la mengua de registros de lluvia durante más de un año.

En nuestro ámbito de estudio, podemos referirnos a una año seco cuando la lluvia total acumulada en ese intervalo representa el $60 \%$ de la cantidad considerada normal en las diversas comarcas. En este caso siempre se cumple, además, que la suma de la precipitación registrada en los dos períodos pluviométricos del año (febrero a mayo, por un lado, y septiembre a octubre, por otro) no alcanza el $50 \%$ de la cantidad total anual normal de los distintos observatorios. Cuantificando este criterio en algunos observatorios del sector analizado, podemos determinar la aparición de un año seco en distintos ámbitos climáticos de las tierras alicantinas:

- Pego: precipitaciones de febrero a mayo inferiores a $300 \mathrm{~mm}$. y a $350 \mathrm{~mm}$. de septiembre a noviembre.

- Elche: precipitaciones inferiores a $100 \mathrm{~mm}$. para ambos intervalos.

- Villena: precipitaciones inferiores a $125 \mathrm{~mm}$. en el intervalo febrero-mayo y a 100 $\mathrm{mm}$. entre septiembre y noviembre.

Desde esta óptica, el año seco tiene una repercusión territorial más restringida. En efecto, años secos pueden afectar una comarca alicantina mientras tiene lugar un intervalo de abundancia pluviométrica en otros, aspecto que se relaciona con la localización de los efectos de episodios de lluvia intensa que hayan tenido lugar en los meses tardo-estivales. Es el caso del año 1982, en el que el episodio de lluvias torrenciales de octubre de 1982 mejora los valores pluviométricos en las comarcas alicantinas del Vinalopó, Campo de Alicante y, en menor medida, en el Bajo Segura mientras que, por contra, se mantiene el ciclo de indigencia pluviométrica en las comarcas septentrionales de la Marina y los Valles de Alcoy.

Las comarcas del Campo de Cartagena y Guadalentín en Murcia, y del Bajo Segura y Bajo Vinalopó (Campo de Elche) en las tierras alicantinas son los espacios más sensibles a sufrir los efectos de reducciones de precipitación en sus producciones agrarias en un año seco y, por ende, los más afectados si las condiciones se prolongan en una secuencia de indigencia pluviométrica.

El mantenimiento de estas condiciones durante un intervalo de tiempo mayor abre una secuencia de indigencia pluviométrica que comprende una sucesión de meses (nunca inferior a dieciseis) con precipitaciones anormalmente menguadas, inferiores, para la mayoría de ellos, en un $40 \%$ a las recogidas en idénticos meses de los años de normalidad pluviométrica.

Una secuencia con indigencia pluviométrica comienza con una reducción radical de lluvias en los meses tardo-estivales (septiembre a noviembre), reducción que continúa en la primavera del año siguiente y culmina con un otoño, de nuevo seco, con precipitaciones claramente inferiores a las normales en el período más lluvioso del año.

Se ha comprobado esencial para el mantenimiento o agravamiento de condiciones de sequía la ausencia de lluvias abundantes en el mes de febrero. Así, para las dos últimas secuencias secas que han azotado las tierras del sureste ibérico las lluvias cuantiosas del mes de febrero de 1985 marcan el cese definitivo de la secuencia seca 1981-84, mientras que la mayor crudeza de la secuencia seca de 1992-94 se deja sentir en este último año por la inexistencia de lluvias abundantes en febrero de 1994 que por el contrario si se producen en febrero de 1992 y 1993, respectivamente.

Con estas premisas, se puede establecer una relación de años secos y secuencias de indigencia pluviométrica para en el sureste ibérico en lo que va de siglo que comprendería los años secos de 1950, 1952, 1955, 1956, 1961, 1966, 1970, 1973, y las secuencias secas desarrolladas entre 1909-1914, 1938-39, 1944-45, y la más reciente de 1981-84, cuyos 
antecedentes se sitúan en los dos últimos años de la década de los setenta, que se prolonga hasta mediados de 1985 en algunas comarcas alicantinas como el Vinalopó y campo de Alicante, por la menor incidencia que aquí tuvieron los episodios de lluvia intensa de febrero de dicho año. Por último, desde octubre de 1992, la reducción de caudales recogidos en la cuenca del Segura ha vuelto a resaltar el problema de sequía en el sureste ibérico, indigencia pluviométrica que, por el momento, se mantiene hasta el final del año hidrológico 1993-94, con grave recrudecimiento de la penuria de lluvias en este último año.

La característica esencial de una secuencia pluviométrica seca -mengua de los volúmenes precipitados - no es, sin embargo, el único rasgo que define este inervalo de tiempo. En efecto, la definición analítica propuesta basada en los valores pluviométricos, se completa con una serie de consideraciones sobre efectos atmosféricos que acompañan el desarrollo de una secuencia seca:

1) Un período de sequía concentra un elevado número de episodios de efectos aciagos que vienen a incrementar los importantes daños asociados a la falta de lluvia. Su relación comprende, en los meses invernales, sucesos de helada y, en los estivales, fenómenos tormentosos con caída de granizo (vid. cuadro $\mathrm{n}^{\circ} 4$ ).

Las heladas se relacionan con la génesis de circulaciones atmosféricas de bajo índice que instalan dorsales subtropicales con eje apuntado hacia el Atlántico norte o Península Escandinava y, cuando la velocidad resulta muy pequeña, configuraciones de retrogresión. Común a ambas es la presencia de altas de bloqueo sobre las tierras europeas que extienden, asimismo, la subsidencia anticiclónica (y, por tanto, la ausencia de precipitaciones), sobre las tierras peninsulares.

La génesis de tormentas estivales con caída de pedrisco se asocia con la presencia de aire frío en altitud que acompaña las acumulaciones superficales de calor sensible. En contra de lo que podría suponerse los meses caniculares de un año seco, como demuestra el estudio de la secuencia pluviométrica seca de comienzos de los años ochenta, no registran valores térmicos máximos extremos en relación con años muy lluviosos e incluso con años pluviométricos normales. Este dato encuentra explicación en la abundancia de circulaciones meridianas norte-sur que adornan la secuencia sinóptica estival en años secos cuyo fundamento reside en el desajuste que sufre la circulación atmosférica en los meses previos al verano marcados por una abundante presencia de dorsales anticiclónicas que determinan anormales acumulaciones de calor en nuestro ámbito, que tienden a reajustarse en los meses de verano.

2) Una sucesión de meses con precipitaciones inferiores a las normales puede verse salpicada por el desarrollos de una episodio de lluvias intensas que, momentáneamente, eleva los volúmenes precipitados siempre con una alto grado de concentración espacial. En nuestro ámbito, la relación entre lluvias intensas y sequía es algo más que la simple dicotomía que caracteriza su realidad climática, puesto que, como se ha señalado, dado el propio carácter de las precipitaciones en las tierras alicantinas, la ausencia de aquéllas determina el postremo desarrollo de un período seco y su génesis suele determinar los límites cronológicos entre epocas húmedas y secas. Es el caso del diluvio caído sobre las tierras alicantinas en octubre de 1982, inserto en el episodio de sequía de comienzos de los años ochenta (1980-84) que permite dividir esta secuencia seca en dos ápices de indigencia pluviométrica (año 1981, por un lado, y 1983-84, por otro) separados por un intervalo de normalidad de lluvias. Además, la concentración espacial de lluvias que acompaña el anárquico comportamiento de un conjunto convectivo de mesoscala en los episodios de lluvia intensa puede aminorar en un ámbito territorial los efectos de una secuencia de indigencia pluviométrica hasta el punto de suprimir el carácter de año seco en dicho espacio. 
EPISODIOS ATMOSFÉRICOS DE EFECTOS CATASTRÓFICOS EN EL SURESTE IBÉRICO ASOCIADOS A AÑOS DE SEQUÍA

\begin{tabular}{|c|c|}
\hline AÑoS SECOS & EPISODIOS ASOCIADOS \\
\hline \multirow{2}{*}{1952,1955 Y 1956} & 4 EPISODIOS DE HELADA \\
1961 & (DESTACA LA HELADA DE FEBRERO DE 1956) \\
& Y PEDRISCOS \\
$1964-1966$ & 3 HELADAS \\
& 5 PEDRISCOS \\
1970 & 4 HELADAS \\
$1978-84$ & 21 PEDRISCOS \\
& 9 HELADAS \\
$1992-94$ & 4 LLUVIAS TORRENCIALES \\
& 3 HELADAS Y \\
& 10 PEDRISCOS \\
\hline
\end{tabular}

Fuente: Elaboración propia.

\section{EVOLUCIÓN DE LAS TEMPERATURAS DURANTE UN AÑO SECO (1981) Y UN AÑO DE ABUNDANCIA PLUVIOMÉTRICA (1989). VILLENA}

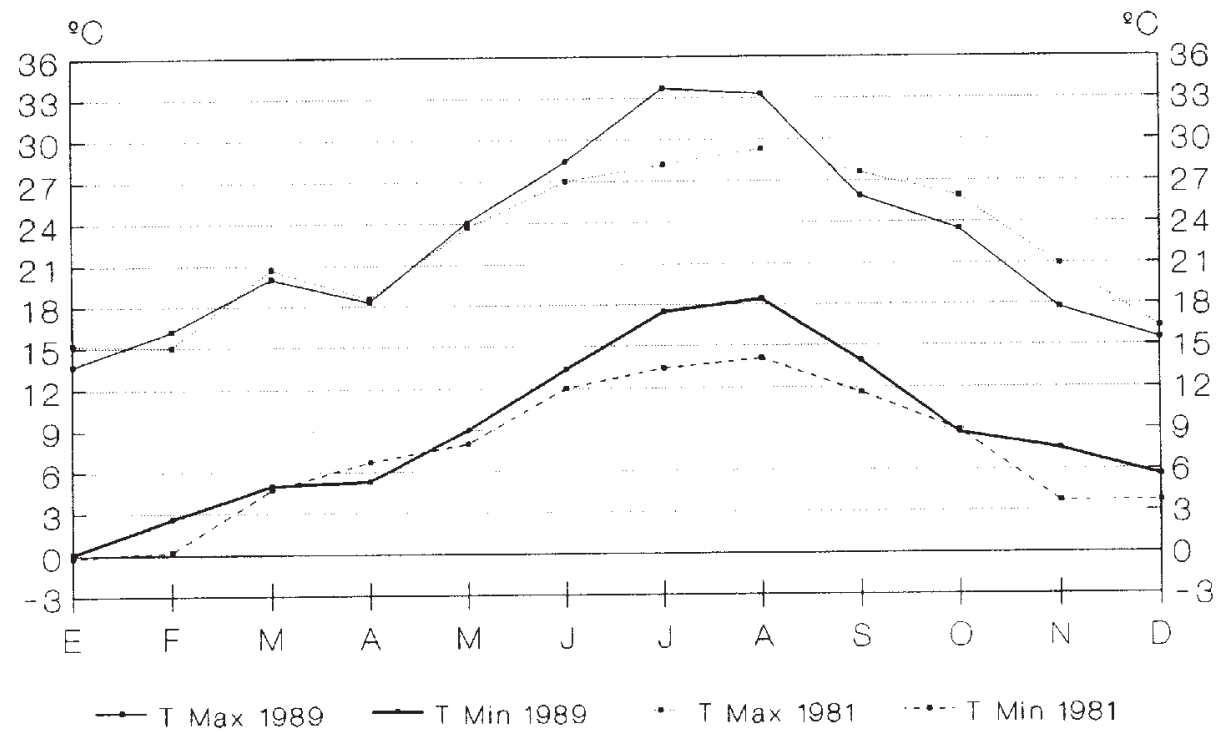

Fuente: Observatorio de Villena. 
3) Por su parte, el análisis de los valores térmicos mensuales registrados a lo largo de un año de indigencia pluviométrica, en relación a los anotados en años de normalidad o abundancia de lluvias ofrece las siguientes peculiaridades (vid. gráfico $\mathrm{n}^{\circ} 3$ ):

- Entre noviembre y abril, los valores medios mensuales de temperatura máxima alcanzados en una año seco son $1^{\circ}$ ó $2^{\circ}$ superiores a los registrados en idéntico intervalo de un año de normalidad pluviométrica. Por contra, los registros mínimos en estos meses fríos del año son menores, entre $2^{\circ}$ y $3^{\circ} \mathrm{C}$, a los anotados en años no secos. Este aspecto, cobra sentido si se tiene en cuenta la abundancia de jornadas con configuraciones atmosféricas de influencia subtropical que se acompañan, junto a la ausencia de lluvias, de elevados porcentajes de insolación que elevan los valores diurnos de temperatura favoreciendo, asimismo, el mayor protagonismo de los fenómenos de irradiación nocturna.

- A partir de mayo, y a pesar de la señalada mayor frecuencia de génesis de «golpes de calor» se observa una equiparación de valores térmicos máximos y mínimos y, paradójicamente, los valores medios calculados para los meses centrales de la época estival (julio y agosto) resultan inferiores en un año seco respecto a años de abundancia o normalidad pluviométrica. Este hecho se relaciona con la mencionada proliferación de fenómenos tormentosos que acompaña un período de mengua pluviométrica motivados por la mayor frecuencia de génesis de expansiones de masas de aire fría que se dirigen hacia las tierras peninsulares insertas en procesos planetarios de reajuste energético. En efecto, la pesistente instalación de dorsales subtropicales en los meses invernales provoca acumulaciones de calor en la franja meridional de las latitudes medias que se acompañan de anormales acumulaciones frías en el casquete polar. En estas condiciones, los procesos de reajuste encuentran, en los meses de verano, período favorable para su desarrollo, lo que condiciona la abundacia de jornadas con presencia, en la escena sinóptica, de vaguadas y depresiones frías de filiación diversa. Ejemplo significativo de ello es el proceso de reajuste energético que tiene lugar en agosto de 1983 que condiciona el desarrollo de una episodio de lluvias intensas en distintos ámbitos de la fachada mediterránea peninsular ${ }^{4}$. En las tierras alicantinas los efectos son particularmente catastróficos en la Marina Alta (Valle del Gorgos) donde los volúmenes acumulados superan los $200 \mathrm{~mm} / 24$ h. en el observatorio de Jalón (220,8 mm., el día 23 de agosto).

\section{Repercusiones territoriales y económicas de sequías y golpes de calor en el sureste ibérico}

Debemos resaltar que la elaboración de una investigación que cuenta entre uno de sus objetivos básicos la evaluación de los efectos territoriales de un hecho climático tan complejo como las sequías no es, en modo alguno, una empresa fácil. Una secuencia continuada de indigencia pluviométrica, al reducir la disponibilidad habitual de recursos de agua, transciende el mero hecho físico y adquiere una notoria relevancia social y económica, difícil de evaluar mediante variables objetivas, al tratarse de un fenómeno de percepción del clima que se manifiesta a veces con grandes contrastes espaciales. Es obvio, que las precipitaciones muy por debajo de los valores medios anuales y acompañadas de temporadas estivales con «golpes de calor», restan eficacia a unas lluvias que, en la región climática del sureste peninsular, son ya, de por sí, escasas. Sin embargo, el hecho que

4 Vid. QUEREDA SALA, J.: La Ciclogénesis y las gotas frías del Mediterráneo Occidental. Excma. Diputació de Castelló, Castellón, 1989, p. 99. 
distingue este déficit habitual de precipitaciones (aridez) de una sequía, no es tanto la mayor magnitud de ese déficit, como la duración más o menos continuada y persistente de una secuencia temporal de indigencia pluviométrica, que acaba culminando con una reducción importante de la disponibilidad natural de agua en las distintas fases del ciclo hidrológico y que culminan con la aparición de una serie de respuestas fisiológicas en los organismos afectados, más perceptibles entre los cultivos de secano.

Además, y como rasgo común a todo el sureste peninsular, los procesos de puesta en valor del territorio han generado, en las últimas décadas, demandas de recursos de agua muy superiores a las disponibilidades naturales. En estos casos, el hombre intenta satisfacer las citadas demandas modificando las distintas fases del ciclo hidrológico para disponer de todos los recursos de agua posibles mediante construcción de embalses para retener las aguas de escorrentía, perforación de pozos para captar las aguas hipogeas y, en último término, trasvases de aguas desde otras cuencas hidrográficas. Sin embargo, estas actuaciones no resultan del todo eficaces si no están inscritas en un marco de planificación hidrológica y, mucho menos, si no existen unas directrices de ordenación territorial solidarias con dicha planificación, saldándose estos procesos con la aparición de un hondo desequilibrio entre demandas y recursos de agua renovables. Por este mismo motivo, la duración de una sequía es, como se ha señalado en el apartado anterior (vid. supra) fundamental, tanto o más que el valor de la mengua de lluvias, al ser éste el factor que determina el volumen global de déficit de recursos. Con la mayor o menor duración de una secuencia seca se asocian, de modo directo, la posible quiebra definitiva de los sistemas de abastecimiento de aguas superficiales, el nivel de sobreexplotación de aguas subterráneas, y el grado de encarecimiento y pérdida de calidad de las aguas utilizadas.

Rebasado el «umbral de sequía», (valor de mengua de recursos hídricos, variable de unas regiones a otras), las repercusiones de una secuencia seca alcanzan no sólo a los cultivos de secano sino que acusan sus efectos los cultivos de regadío, disparándose así el volumen de pérdidas económicas. De esta forma, al alejarse los cultivos practicados de los óptimos ecológicos, se reducen cosechas en cantidad y calidad, menguan las superficies de regadío, dejan de sembrarse variedades de ciclo corto y gran valor comercial como las hortalizas. La gravedad de los daños ocasionados en la actividad agraria puede verse acrecentada si a la situación de sequía se aúnan, como se ha señalado, «golpes de calor» estivales que, como ha ocurrido en los estíos de 1981, 1982, 1983, ó 1994 acaban por ahogar unas plantas ya de por sí debilitadas por la carencia de agua.

El catálogo de repercusiones económicas y territoriales de una secuencia de sequía se acompaña, además, de efectos en los sistemas de captación y distribución de agua para abastecimiento urbano, así como consecuencias en una serie de recursos naturales como masas arboreas (incendios forestales), espacios lagunares (desecación natural) y recursos cinegéticos.

\subsection{Repercusiones de las sequías sobre los recursos de agua}

La reducción de precipitaciones en una secuencia temporal de varios años, conlleva implicaciones importantes en las dos fases del ciclo hidrológico que el hombre ha modificado mediante obras de infraestructura hidráulica para satisfacer sus necesidades, es decir, embalses de regulación de aguas superficiales, y obras de captación de aguas subterráneas mediante sondeos y minados. La irregularidad interanual de las precipitaciones en el sureste de la Península Ibérica condiciona que el volumen de recursos de agua renovables

5 CHARRE, J.: «A propos de la secheresse», en Revue Geographique de Lyon, n 52, pp. 215-216. 
a disposición del hombre ofrezca fuertes desequilibrios espaciales; aspecto éste de gran actualidad al calor de la elaboración de los planes hidrológicos de cuenca conducentes a la redacción de un Plan Hidrológico de ámbito estatal. En primera aproximación, sólo dos comarcas de este ámplio espacio regional (Marina Alta y montaña alcoyana) tienen garantizada, en la actualidad, una disponibilidad de recursos de agua renovables suficientes para poder atender las demandas generadadas por los procesos de urbanización, industrialización, actividad turística y, sobre todo, nuevos regadíos. Recursos no exentos, empero, de problemas de contaminación por intrusión marina en la franja costera, vertidos urbanos, industriales, y lixiviados de fertilizantes agrarios, que precisan, como en el reso del territorio analizado, de urgente corrección si no se quiere amenazar su utilización futura. El resto de comarcas, tanto las inscritas en los sistemas de explotación del Júcar, como las adscritas al Organismo de Cuenca del Segura, adolecen de importantes déficits de agua para alimentar las demandas actuales.

Sirva como ejemplo, que el volumen total de recursos hídricos disponibles en el ámbito

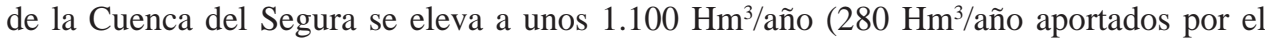
Trasvase Tajo-Segura), mientras que los recursos no renovables procedentes de la explotación de reservas de acuíferos y los reutilizados se elevan a $440 \mathrm{Hm}^{3} / a n ̃ o$, ascendiendo, así, el volumen total de recursos a $1.600 \mathrm{Hm}^{3} /$ año. Volumen totalmente insuficiente para satisfacer las demandas actuales y, mucho menos, las previsiones de incremento a medio plazo que maneja el organismo de Cuenca del Segura (vid. cuadro $n^{\circ} 5$ ). En consecuencia, si en la actualidad ya se establece una relación de desequilibrio entre recursos renovables (unos $1.100 \mathrm{Hm}^{3}$ ) y usos consuntivos (unos $1.566 \mathrm{Hm}^{3}$ ) cifrable en casi $500 \mathrm{Hm}^{3} /$ año, las secuencias de sequía, aunque coyunturales, no hacen sino que acrecentar ese déficit y manifestar, en mayor medida, la escasa elasticidad de los sistemas actuales de captación y distribución de recursos de agua frente a dichas situaciones.

Cuadro 5

USOS CONSUNTIVOS DEL AGUA Y PREVISIONES DE DEMANDA EN EL ÁMBITO DE LA CONFEDERACIÓN HIDROGRÁFICA DEL SEGURA (gasto en $\mathrm{Hm}^{3}$ )

\begin{tabular}{|c|c|c|c|}
\hline USOS & ACTUAL & AÑ 2002 & AÑ 2012 \\
\hline URBANO & 200 & 294 & 376 \\
INDUSTRIAL & 38 & 50 & 58 \\
AGRARIO & 1.328 & 1.923 & 2.106 \\
\hline TOTAL & 1.566 & 2.267 & 2.540 \\
\hline
\end{tabular}

Fuente: Proyecto de Directrices. Confederación Hidrográfica del Segura. (Las previsiones de demanda corresponden a estimaciones teóricas). Elaboración Propia.

Por mucho éxito que se presuma al citado Plan Hidrológico Nacional en la corrección de desequilibrios espaciales mediante una política de trasvases, lo cierto es que sería todo un logro para la Cuenca del Segura que se alcanzase el volumen previsto, por ley, (600 $\mathrm{Hm}^{3}$ ) en la primera fase del Aprovechamiento Conjunto Tajo-Segura. Aún así, si se verificasen las previsiones que maneja el organismo de Cuenca del Segura sobre la evolución de la demanda en los distintos usos consuntivos, a medio plazo (horizonte del año 2002) el déficit de recursos actual no sólo no menguaría sino que se incrementaría y, con 
ello, también el riesgo potencial de daños económicos ante futuras secuencias de indigencia pluviométrica.

Idéntico signo preside la situación de los recursos de agua en las comarcas de la provincia de Alicante adscritas a la Confederación Hidrográfica del Júcar, especialmente las pertenecientes a la región climática del sureste peninsular; es el caso del sistema de explotación Vinalopó-Campo de Alicante, y del sistema de explotación Marina Baja. En ambos casos, el balance de demandas y disponibilidades de agua es netamente deficitario, en $10 \mathrm{Hm}^{3}$ para la Marina Baja y 325,15 $\mathrm{Hm}^{3}$ en el sistema Vinalopó-Campo de Alicante. En este último sector, el importante déficit es parcialmente subsanado mediante el trasvase de aguas desde el ámbito del Segura $\left(100 \mathrm{Hm}^{3}\right.$ procedentes del Trasvase Tajo-Segura y sobrantes del Segura, transferidos a dicho sistema de explotación a través de la Mancomunidad de Canales del Taibilla y Comunidad de Regantes de Levante (margen izquierda). Son éstos, valores cuantitativos que conviene tener presentes a la hora de ponderar el carácter climático o «humano» de las secuencias de sequía.

En el Sureste Ibérico el único colector fluvial que aporta unos volúmenes de agua superficial importantes es el río Segura cuya cabecera (río Mundo) recibe además las aportaciones del Trasvase Tajo-Segura (unos $280 \mathrm{Hm}^{3} /$ año de media desde 1979). Si bien, aún tratándose de una de las cuencas hidrográficas mejor reguladas del territorio peninsular, el caudal útil anual regulado está próximo a $800 \mathrm{Hm}^{3} / a n ̃ o$, a los que se añaden $246 \mathrm{Hm}^{3}$ del embalse de la Pedrera, integrante de la infraestructura del Postrasvase Tajo-Segura (Canal del Campo de Cartagena y red primaria de la Mancomunidad de Canales del Taibilla).

A la vista de los recursos disponibles, se precisa, pues, una explotación eficaz de los recursos almacenados en embalses con el fin de amortiguar en la medida de lo posible la incidencia de períodos de sequía extrema. Así, por ejemplo, en la sequía de 1980-1984, la utilización de las reservas acumuladas en los embalses y el empleo de los recursos que empezaban a llegar a la Cuenca desde la cabecera del Tajo (Entrepeñas y Buendía), no bastaron para evitar unas pérdidas económicas en el sector agrario valoradas en 20.000 millones de pesetas (ptas. corrientes de 1983) ${ }^{6}$. En efecto, tras unos años de normalidad o, incluso, abundancia de lluvias entre 1971 a 1977, en los que se pudo atender unas demandas crecientes, sobre todo por la expansión de nuevos regadíos (ante la expectativa de la llegada de las aguas del Trasvase Tajo-Segura) y, además, aportar unas reservas de agua que más tarde serían de inestimable ayuda para afrontar el muy seco año de 1978, (con unas lluvias acumuladas inferiores en un 52,5\% al volumen medio anual, lo que provocó una sucesión de desembalses cifrados en $684,7 \mathrm{Hm}^{3}$ ) se sucederán los años muy secos de la referida sequía 1981-1984, en los que los desembalses del Segura, sumados a las primeras aguas del Tajo que empezaban a llegar con cierta generosidad a la cabecera del río Mundo, lograron paliar, en un primer momento, los efectos de la penuria pluviométrica durante 1981 y 1982, pero no en cambio durante 1983 y 1984 ya que los desembalses, una vez agotadas las reservas, y reducidos los recursos trasvasados desde el Tajo, fueron incapaces de evitar los elevadísimos daños producidos en el regadío del sureste peninsular cuya extensión alcanzaba, entonces, casi un cuarto de millón de hectáreas.

Similares premisas coinciden en la todavía inconclusa secuencia de sequía de comienzos de los noventa (1992-94) sólo que, en la actualidad, la superficie ocupada por los regadíos (260.000 ha.), es superior a la de 1983 y el peso relativo de los usos urbanos del agua han pasado de consumir $137 \mathrm{Hm}^{3}$ en el año 1983 a $183 \mathrm{Hm}^{3}$ en 1993, distribuidos en

6 ZAPATA NICOLÁS, M. et alii.: Repercusiones económicas de la sequía 1980-1983 en el sector agrario de la Cuenca del Segura. C.S.I.C., Murcia, 1990, 237 pp. 
su mayor parte por la Mancomunidad de los Canales del Taibilla que abastece a una población próxima a 2 millones de habitantes de las provincias de Murcia y Alicante.

De manera que, con un nivel de demandas mucho mayor que a comienzos de los años ochenta, las disponibilidades de agua trasvasada desde la cuenca alta del Tajo y los desembalses de aguas propias del río Segura (vid. gráficos $n^{\circ} 4 \mathrm{y} \mathrm{n}^{\circ}$ 5) han sido incluso, inferiores a los de la sequía 1980-1984, con particular gravedad en los volúmenes del año 1994, en el que los desembalses y las aportaciones del Tajo apenas sumaban —agosto de 1994- $376 \mathrm{Hm}^{3}$, es decir, $7 \mathrm{Hm}^{3}$ menos que en el año seco 1983, hecho que delata la gravedad de la situación vivida en las tierras del sureste ibérico en el verano de 1994.

No menos importantes han sido, por su parte, las repercusiones de las secuencias de indigencia pluviométrica sobre las aguas subterráneas. A falta de recursos de agua superficiales, la satisfacción de demandas en buena parte del sureste peninsular se ha resuelto con la extracción masiva de aguas hipogeas alojadas en mantos freáticos que, debido a la configuración morfoestructural que presentan, ofrecen serios riesgos de salinización, tanto por intrusión marina (acuíferos costeros) como por lixiviación de sales evaporíticas triásicas (acuíferos subbéticos y prebéticos). Contaminación y reprofundización continua de sondeos, son procesos que en modo alguno se deben a las secuencias de sequías pero que se ven incrementados cuando éstas acontecen. En efecto, en años de normalidad pluviométrica los balances de entradas y salidas de muchos de los acuíferos de la provincia de Alicante y de la Región de Murcia, es netamente deficitario. Además, en el propio Plan Hidrológico de la Cuenca del Segura se admiten valores de explotación de reservas no renovables de $310 \mathrm{Hm}^{3} /$ año, superando, de este modo, el volumen medio de aguas llegadas de la cuenca alta del Tajo (unos $280 \mathrm{Hm}^{3} /$ año). Ahora bien, un aspecto evidente comprobado por el trabajo de campo es que los años de sequía provocan hondos efectos en el alumbramiento de aguas subterráneas, al incrementarse el nivel de sobreexplotación, el número de pozos perforados, la profundidad de extracción, los precios de venta y, en el peor de los casos, el cierre de muchos sondeos por agotamiento o por salinización. Así por ejemplo, el mayor dinamismo en la construcción de pozos de toda la provincia de Alicante, en lo que va de siglo se registra en el trienio 1983-1985 con un volumen de tramitación de expedientes, por parte de la sección de Minas de la Consellería de Industria superior al millar de solicitudes de construcción de sondeos (vid. gráfico $\mathrm{n}^{\circ} 6$ ). La reciente secuencia seca (1992-94) no ha hecho sino agravar los negativos efectos sobre los sistemas acuíferos del sureste peninsular que fueron denunciados por diversos organismos, públicos y privados, a comienzos de los años ochenta. Particularmente dañados están los acuíferos de el Campo de Cartagena, litoral de Águilas-Mazarrón ${ }^{7}$, Fosa del Guadalentín, e incluso con mayor intensidad, los de las comarcas alicantinas del Bajo Segura (sobreexplotación del acuífero de Cabo Roig) ${ }^{8}$ y Vinalopó (extinción del acuífero de la Sierra del Cid).

Muy expresivo resulta el comentario de los efectos de la reciente sequía 1992-94 sobre los usos agrarios del agua (vid. cuadros $\mathrm{n}^{\circ} 6 \mathrm{y} \mathrm{n}^{\circ} 6$ bis) obtenidos mediante trabajo de campo. Tras identificar el origen de las aguas empleadas en las comarcas alicantinas, con excepción de la Montaña Central de Alicante, se han agrupado los efectos detectados atendiendo a su naturaleza:

7 GIL OLCINA, A.: «Aridez, riego localizado y agricultura de vanguardia en el litoral murciano de Águilas» en Los Paisajes del Agua. Instituto Universitario de Geografía de la Universidad de Alicante y Universidad de Valencia. 1989, pp. 213-222.

8 VERA REBOLLO, J. F.: Tradición y cambio en el campo del Bajo Segura. Instituto de Estudios Alicantinos, Alicante, 1984, p. 219. 


\section{RELACION ENTRE LAS EXISTENCIAS DE AGUA Y LOS CONSUMOS MINIMOS CALCULADOS PARA EL RIEGO. CUENCA DEL SEGURA. 1990-1994.}

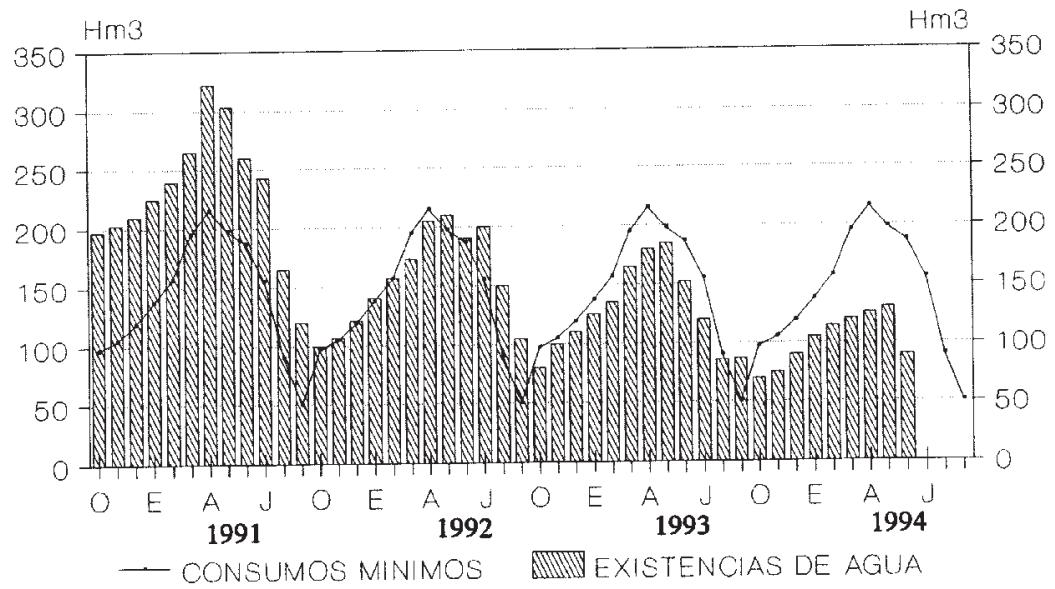

Fuente: Confederación Hidrográfica del Segura.

GRÁFICO N ${ }^{\circ} 4$

\section{DESEMBALSES Y APORTACIONES DEL TRASVASE TAJO-SEGURA EN LA CUENCA DEL SEGURA. RELACIONES CON LAS SEQUIAS. 1980-1994}

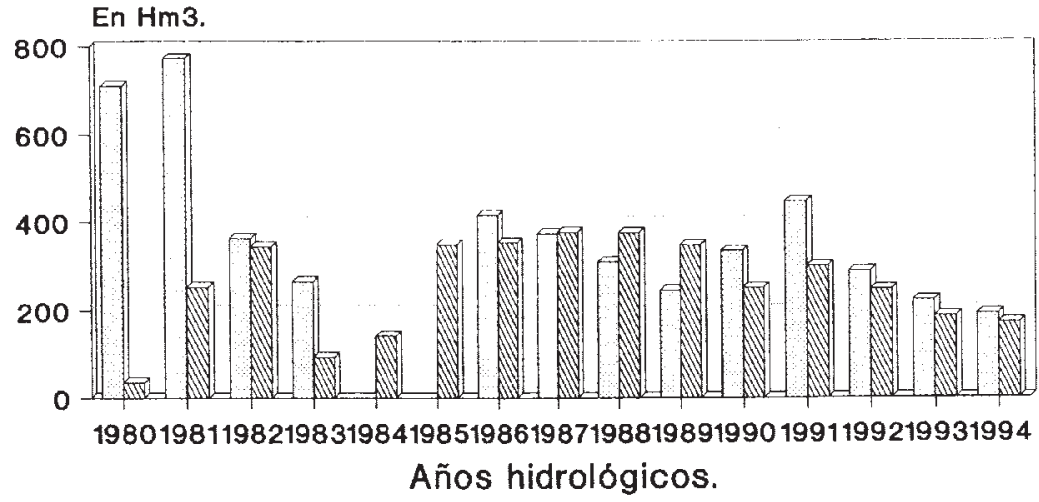

\section{$\square$ Desembalses Segura Trasvase Tajo-Segura}

Fuente: Comisaría de Aguas de la

C.H. Segura y S.C.R. Acueducto Tajo-Segura

Elaboración Propia. 
$N^{2}$ DE POZOS PUESTOS EN FUNCIONAMIENTO EN LA PROVINCIA DE ALICANTE. 1977-1985

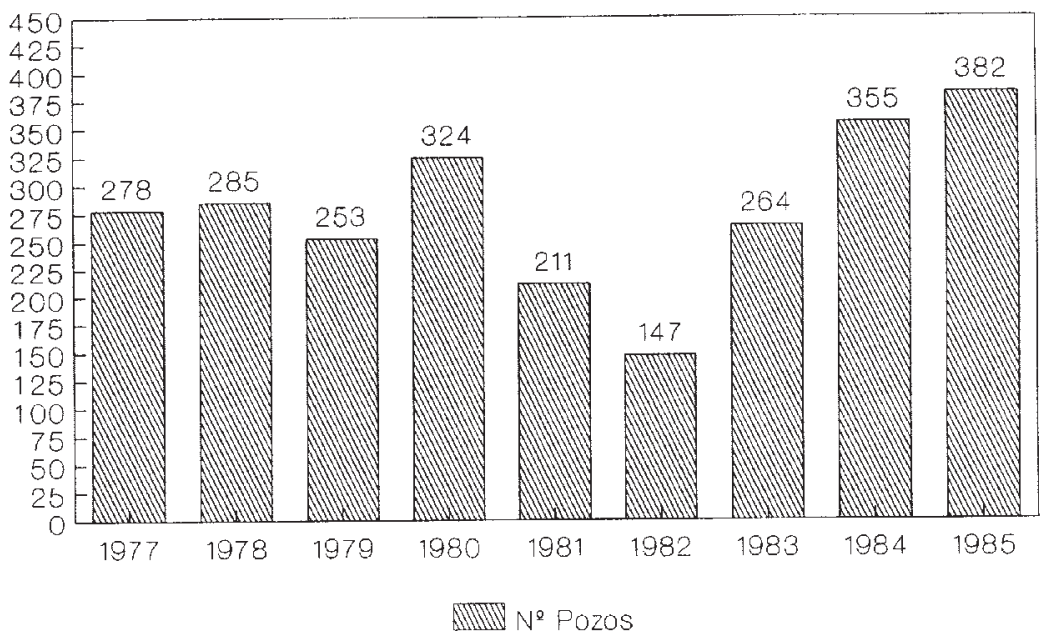

Fuente: Consellería de Industria.

Generalitat Valenciana.

GRÁFICO N ${ }^{\circ} 6$

EFECTOS DE LAS SECUENCIAS DE SEQUIA SOBRE LA EXPLOTACION DE SISTEMAS ACUIFEROS. SIERRA DE CREVILLENTE 1980/93

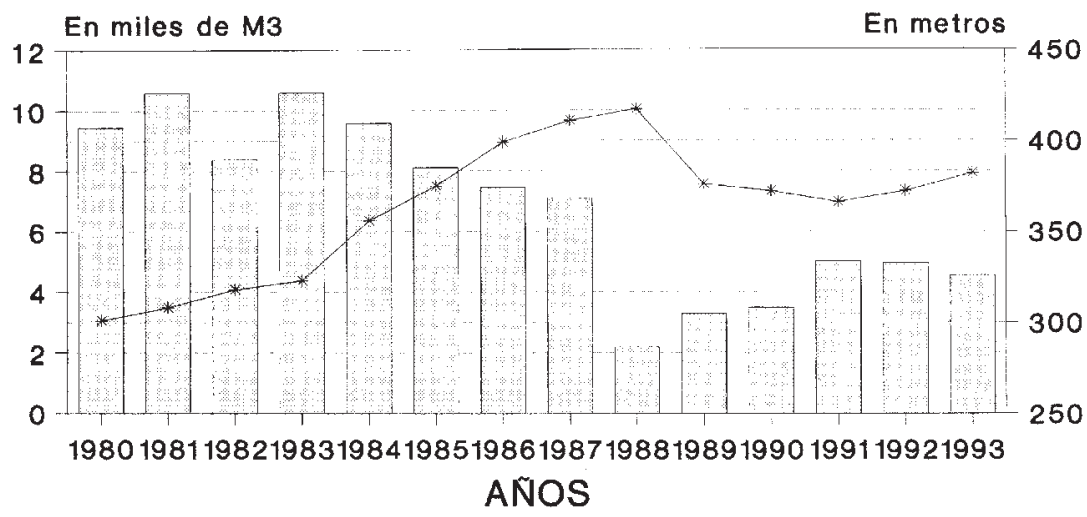

Gasto en miles de M3 - * Nivel Estático (m.)

Fuente: Vicente Mira, S.A.T. 3.819 de Aspe (Alicante). Elaboración Propia.

GRÁFICO N 7 


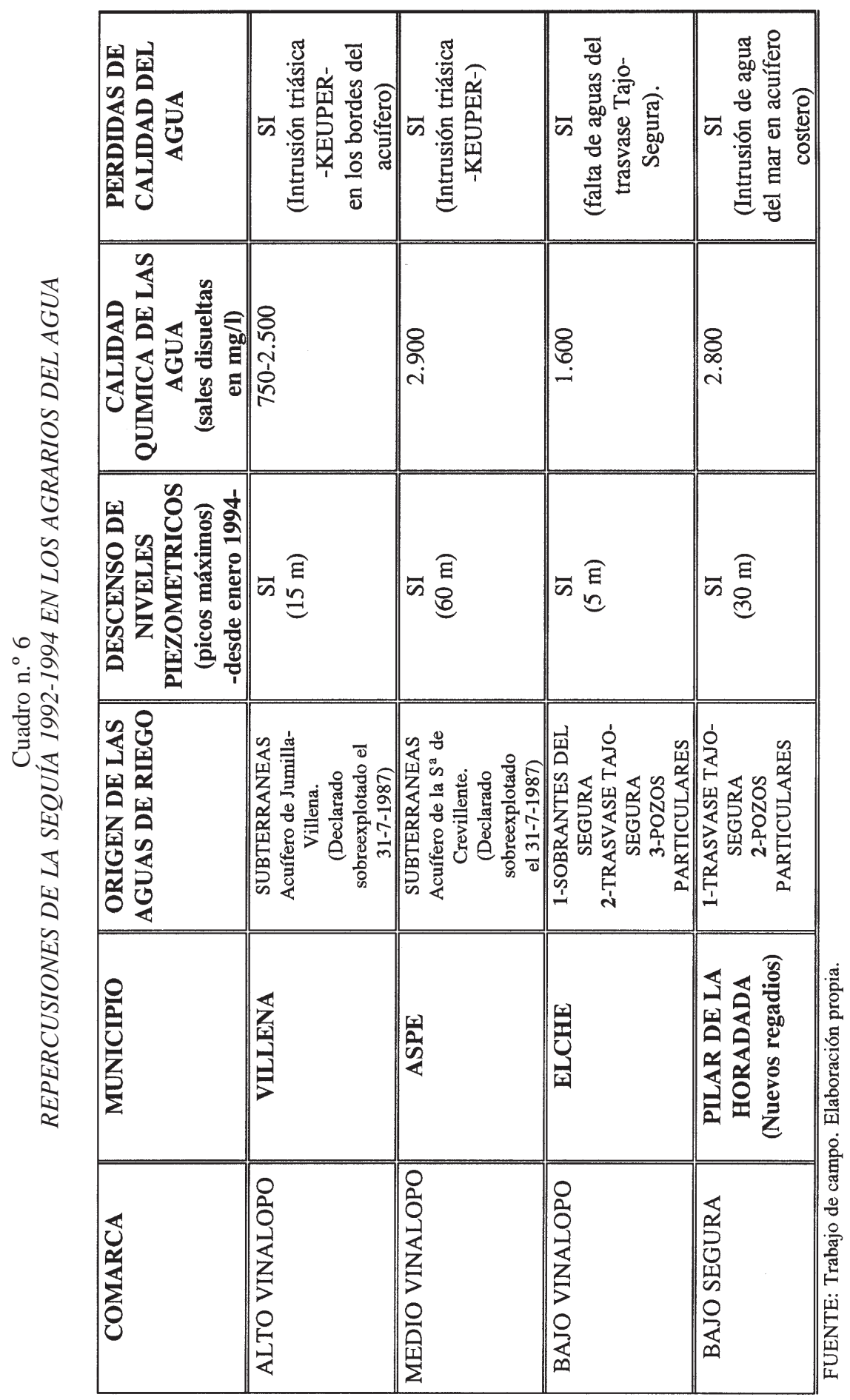




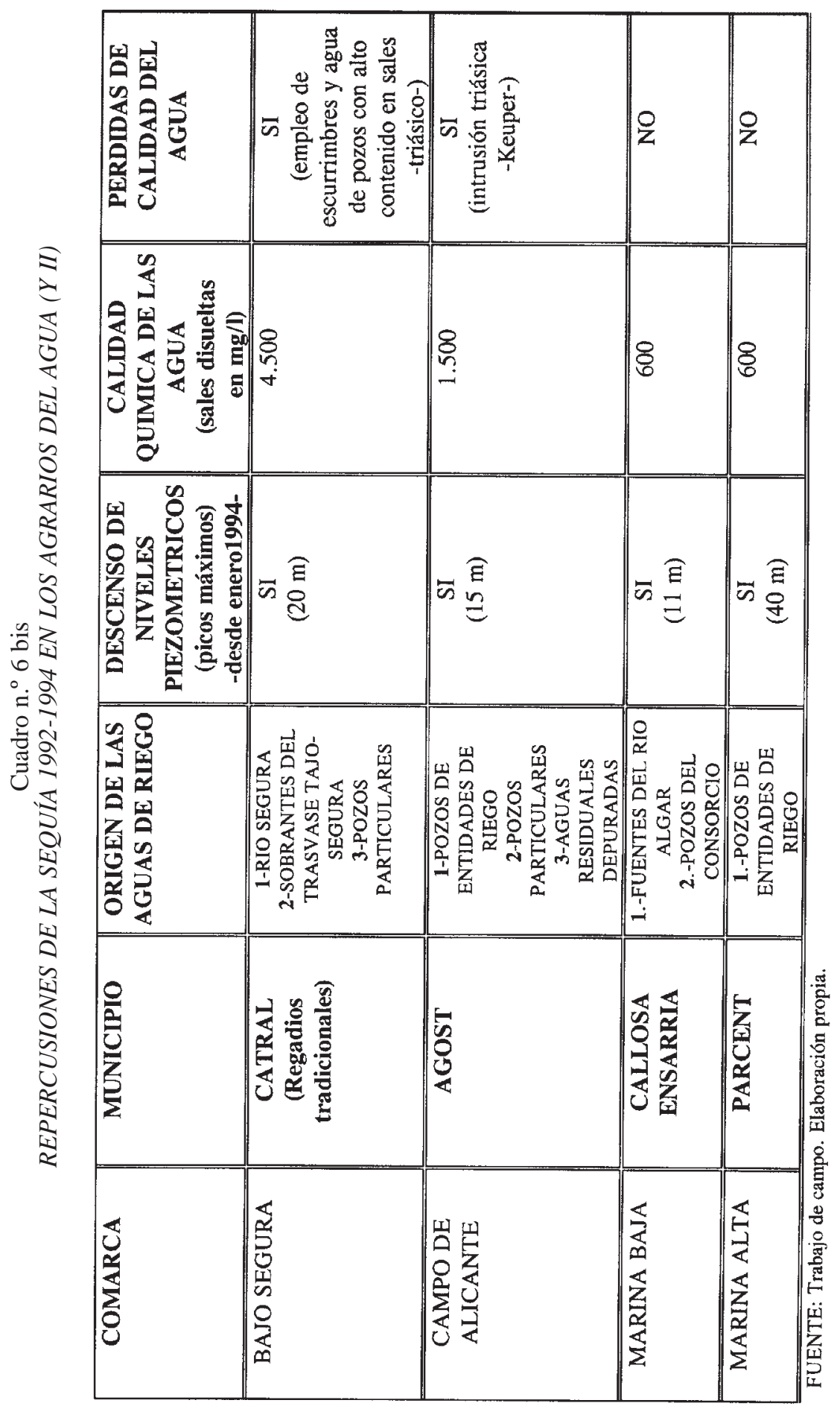


- En todas las comarcas, tras intensificarse los niveles de gasto de agua para riego (el gasto de otros usos consuntivos no ha variado en demasía), se han verificado descensos muy notables de los niveles piezométricos, que oscilan desde los 5 metros por año del Campo de Elche, hasta los 60 metros medidos por el piezómetro en el acuífero sobreexplotado de la Sierra de Crevillente (Medio Vinalopó), que sitúan la profundidad de extracción del agua (450 m.) por debajo del nivel del mar (vid. gráfico $\mathrm{n}^{\mathrm{o}} 7$ ).

- De idéntica forma, la mayor intensidad de explotación ha desequilibrado aún más el frágil equilibrio hidrodinámico en que se encuentran todos estos acuíferos, y ha agravado los procesos de contaminación química que les afectan, destacando los $4.500 \mathrm{mg} / \mathrm{l}$ de las aguas alumbradas en unos pozos (unos 500 1/s de aforo) de la Sierra de Callosa del Segura, que han visto revalorizado no sólo su uso (al menguar las dotaciones del río Segura y Trasvase) sino tambien su precio, alcanzándose cotizaciones, pese a su ínfima calidad, al lucrativo precio de $16 \mathrm{ptas} / \mathrm{m}^{3}$. Estas aguas se han destinado al riego de granados y palmáceas de los municipios de Redován, Callosa del Segura, Cox, y Catral. Mientras tanto, aguas abajo de la margen izquierda del río Segura, en los muncipios de Dolores y San Fulgencio, el resto de regadíos tradicionales se han conformado con la utilización de las llamadas aguas de escurrimbres que, como su propio nombre indica, son aguas de desecho de utilizaciones varias, viciadas con todo tipo de productos químicos imaginables que son reelevadas mediante motores a la red de riego desde pequeñas charcas y estanques donde se almacenan los exangues caudales de aguas muertas circulantes por la red de escorrederas, meranchos, y azarbes. Al disminuir, por la falta de lluvias, el riego con aguas vivas, las concentraciones de elementos contaminantes de las aguas muertas es harto elevado, tanto que los agricultores que han osado emplearlas para intentar salvar la cosecha de cítricos, melón, e incluso el sufrido algodón, reparaban pronto en su error al comprobar que, a las pocas horas de practicado el riego, las plantas se marchitaban y fallecían. En estos municipios del Bajo Segura, donde dominan los regadíos tradicionales, las escasas aguas que se han distribuido merced al riego de socorro concedido por el Consejo de Ministros a finales de julio, no alcanzaron, por diversos motivos, los predios a los que iban destinados: extracciones clandestinas desde los acueductos del Postrasvase (ramal de Crevillente y ramal del Campo de Cartagena), pero sobre todo, infraestructuras de riego desfasadas y preparadas para distribuir tan sólo grandes cantidades de agua, eran incapaces de completar las tandas (de unos 500 l/s) que se precisan para irradiar las aguas por todos ramales y brazales de riego, contribuyendo con ello a acentuar un clima de malestar social e inclusive de enconados enfrentamientos, entre agricultores de un mismo municipio.

- Menos uniforme ha sido el comportamiento, a nivel provincial, del incremento de precios del agua y la disminución de dotaciones medias de agua para riego (vid. cuadro $\mathrm{n}^{\circ}$ 7). Las únicas comarcas alicantinas que han experimentado subidas apreciables en la cotización del agua por la sequía han sido el Bajo Segura y el Medio Vinalopó. Por ejemplo, en el Bajo Segura, al incremento ya citado de los precios del agua en el sector de regadíos tradicionales (a unas 16 ptas $/ \mathrm{m}^{3}$ ), ha acompañado el ascenso de precios detectado en el municipio del Pilar de la Horadada, donde las aguas alumbradas (acuífero costero de Cabo Roig) han sido vendidas durante el verano de 1994 a 90 ptas $/ \mathrm{m}^{3}$, pese a la elevada salinidad que presentan $(2.800 \mathrm{mg} / \mathrm{l})$, siendo adquiridas mayormente por pequeñas y medianas empresas agrarias dedicadas al cultivo de alcachofa9 ${ }^{9}$ Por lo que respecta a la

9 Algunas de estas empresas, por efecto de la reciente secuencia de sequía (1992-94) y de las restricciones de agua del Trasvase Tajo-Segura, han aprovechado las tierras tierras de regadío abandonadas del Medio Vinalopó procediendo al arrendamiento de fincas de gran tamaño (pagos de la Casa Costera, Serreta y Casa Bigote), en las que han podido sembrar alcachofas y habas merced a la utilización de aguas subterráneas. 


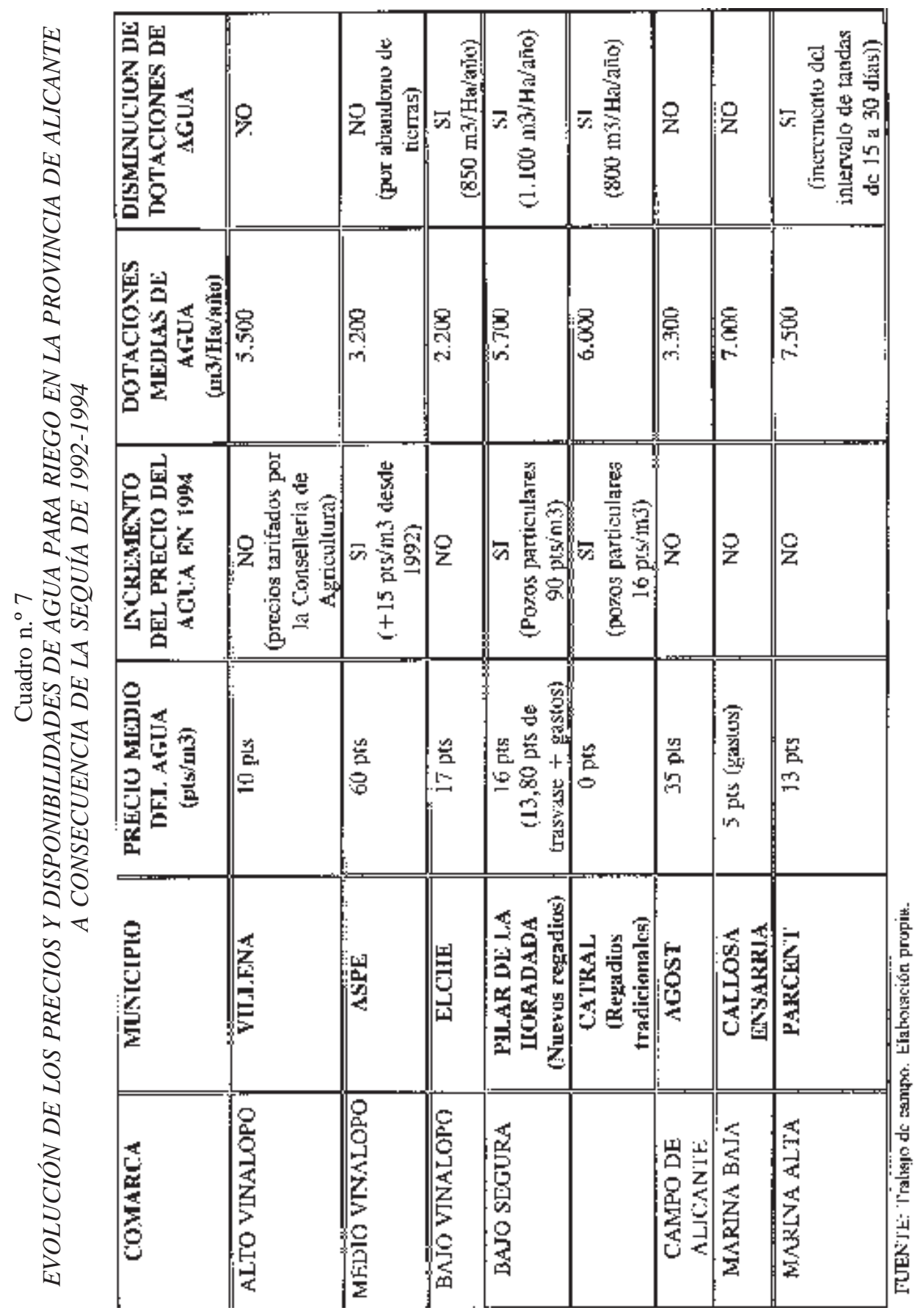


mengua de las dotaciones medias de agua para riego por efecto de la sequía, ésta se ha producido en aquellas comarcas con una fuerte dependencia hacia los recursos de agua del río Segura y Trasvase Tajo-Segura destacando que ni en el Bajo Segura ni en el Bajo Vinalopó se ha dispuesto de dotaciones superiores a $1.100 \mathrm{~m}^{3} / \mathrm{ha} / \mathrm{año}$, cantidad que apenas ha sido suficiente para aplicar un riego de supervivencia para los cultivos arbóreos, mientras las hortalizas sufrían un «barbecho forzado». En el norte de la provincia de Alicante destaca el municipio de Parcent puesto que si bien no se han vivido experiencias tan dramáticas como en el Bajo Segura y Bajo Vinalopó, la reducción de lluvias ha condicionado el aumento de las tandas de riego (de 15 a 30 días) practicado por la Sociedad Agraria de Transformación de dicha localidad a raíz de la mengua de productividad del pozo que explota dicha entidad por sobreexplotación (se crea un cono de descenso de gran amplitud).

\subsection{Efectos de sequías y golpes de calor en el sector agrario}

La evaluación de daños y superficie territoriales afectada por efecto de una secuencia de sequía se presenta como la tarea más difícil dentro de las cuantificaciones de daños ocasionadas por eventos atmosféricos de signo aciago, pues las estadísticas agrarias oficiales que reflejan el estado de superficies de cultivo y rendimientos agrarios, al ofrecer datos a escala provincial, impiden pormenorizar las repercusiones de este riesgo climático. Las únicas fuentes que permiten evaluar estos daños, con cierta precisión, es, ante todo, el trabajo de campo, que se completa con la consulta crítica - los daños suelen adolecer a veces de exageraciones - de informes oficiales elaborados por los organismos agrarios correpondientes (Consejerías de Agricultura, Servicios de Extensión Agraria, Cámaras Agrarias). Los efectos de las sequías no son en absoluto uniformes en el espacio, existiendo hondas diferencias intercomarcales en la duración de las secuencias y en el grado de los daños.

Por otro lado, para entender la diferente percepción social y los efectos territoriales de la sequía de comienzos de los años ochenta respecto a la actual-, resulta básico destacar la diferente dinámica agraria que acompaña ambas secuencias de indigencia pluviométrica. En efecto, hace diez años, la dinámica de los regadíos surestinos era claramente expansiva bien por las expectativas que despertó la llegada de aguas del Acueducto Tajo-Segura y por las esperanzas que se depositaron en la competitividad de las producciones hortofrutícolas españolas en los mercados de la Comunidad Económica Europea. Por el contrario, en la actualidad, el incumplimiento de todas las previsiones contenidas en la Ley 52/1980 sobre aprovechamiento conjunto Tajo-Segura (vid. infra) y la escasa competitividad de muchas líneas de producción hortofrutícolas en los mercados de la Unión Europea, han provocado el abandono de numerosas explotaciones agrarias, más aún si se añaden los efectos aciagos de una secuencia seca.

En primera aproximación, disminución de superficies de cultivo, menguas de productividad, y pérdidas de calidad, constituyen el corolario más visible de las secuencias de indigencia pluviométrica sobre el sector agrario.

Muy cuantiosos resultan ante un evento de sequía los daños en las agriculturas de secano. Particularmente afectadas, resultan las comarcas alicantinas del Vinalopó, Campo de Alicante y Bajo Segura. El trabajo de campo ha revelado como ni siquiera en sectores con los cultivos ubicados sobre suelos con mayor humedad subsuperficial en umbrías, ramblizos, o conos aluviales, han logrado soportar los efectos de la falta de lluvias llegando incluso a producirse la muerte fisiológica de la planta al alcanzar un punto de marchitez permanente que impide la extracción de agua a las raíces. Así ha sucedido con bastantes 
plantaciones marginales de vid y almendros en secano venidas a menos por la duración de la sequía (1992-94), y asimismo, en plantaciones de cultivos herbáceos, sobre todo cereales y girasol que no llegaban siquiera a germinar. Como se ha indicado, existe una carencia absoluta de trabajos oficiales de evaluación de daños y sólo puede presentarse, al respecto, la valoración de superficies cultivadas del Ministerio de Agricultura. Puede afirmarse, sin riesgo de equivoco que las 93.000 ha de secano existentes en el Vinalopó, Campo de Alicante, y Bajo Segura en 1989, se han reducido, cinco años después a 70.000 has. La reducción de lluvias de estos últimos años ha contribuido a agravar decisivamente los problemas de mercado de unas producciones que arrojan resultados económicos incapaces de costear apenas el importe de su recolección.

Muy notorios han sido, al respecto, los efectos de la reciente secuencia de sequía (199294) en las tres producciones más representativas de la agricultura de secano tradicional del sureste ibérico:

- así, en la almendra, el trauma fisiológico auspiciado por la penuria de lluvias, y acentuado sin duda por el golpe de calor de principios de julio de 1994, derivó no sólo en contracciones importantes de producción en bruto, del orden del $50 \%$, sino que, además, ha descendido de un $25 \%$ a un $20 \%$ el rendimiento neto determinado por la cantidad de almendra en cáscara necesaria para completar un kilogramo de almendra en gallón, ocasionando, a su vez, el descenso del precio medio obtenido en la campaña de 1994 en relación a la anterior (de 130-140 ptas/kg a 105-115 ptas/ $\mathrm{kg}$ ), agravando así las consecuencias de una mayor penetración de almendra californiana (vid. foto $\mathrm{n}^{\circ} 1$ ).

- en la vid, los efectos han sido similares, pues igualmente hay plantaciones que muy difícilmente podrán ser recuperadas en condiciones óptimas de explotación, visto el elevado número de cepas que se han secado. A ello se añade una proporción mucho mayor de vides que han desplegado pámpanos y sarmientos de escasa longitud sin apenas fruto, y que, además, exigen podas de viva y ciega para la siguiente campaña. De esta manera, durante la vendimia de 1994, adelantada varias semanas a sus fechas habituales, la cantidad de cosecha recolectada ha disminuido entre un $40 \mathrm{y}$ un $60 \%$ de las productividades habituales alcanzadas en secano, hecho al que también ha contribuido la señalada «ola de calor» de principios del mes de julio al propiciar la quema total o parcial de muchos racimos, particularmente en la comarca alicantina del Vinalopó.

- por su parte, en olivo, la evaluación de daños resulta muy difícil al solaparse los efectos de la sequía de 1994 con la vecería que caracteriza este cultivo de secano. No obstante, las previsiones de cosecha para la campaña 1994 son prácticamente nulas como manifiesta el incremento acusado de precios del aceite, superando las $500 \mathrm{ptas} . / \mathrm{l}$.

Menos complejo resulta el análisis de daños en la agricultura de regadío por la proliferación de informes elaborados desde diferentes organismos debido al tradicional carácter reivindicativo de la actividad de regadío en las tierras del sureste ibérico. Vega Media murciana, Campo de Cartagena y Guadalentín en la región de Murcia y Bajo Segura y Bajo Vinalopó en la provincia de Alicante son las comarcas en mayor grado afectadas por las secuencias de sequía. El trabajo de campo realizado en estas dos últimas permite establecer los siguientes aspectos. Debemos señalar en primer lugar que estas dos comarcas no sólo suponen casi la mitad de los regadíos totales existentes en la provincia de Alicante, sino que además se destacan por potenciales productivos de gran participación en la producción final agraria provincial, harto importantes en hortalizas (10.300 has), naran- 


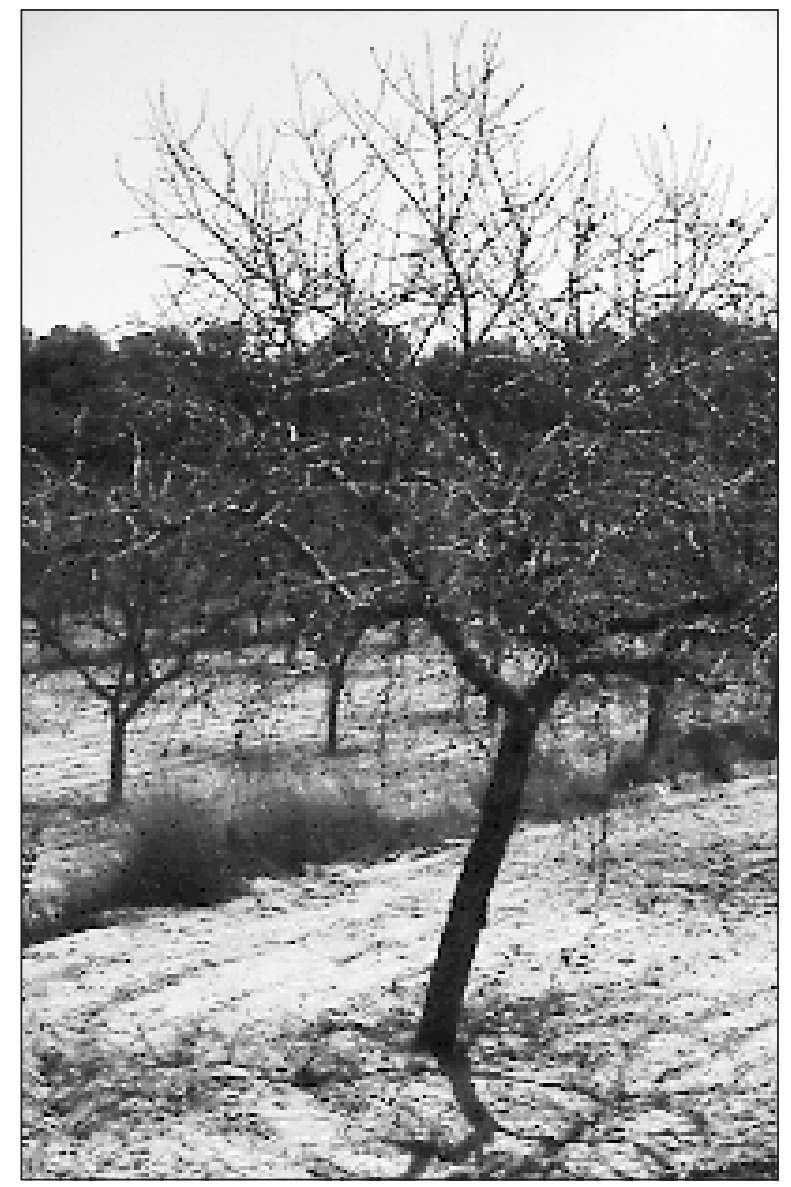

Fото No 1. Estado fisiológico de los almendros en Rebate (Orihuela). Agosto 1994.

jas y mandarinas (13.000 has), limones (14.500 has), almendro en sistema intensivo (8.400 has), granado (2.200 has), y en ornamentales (300 has) como flores para cortar o palmáceas con rentabilidades económicas que alcanzan en rosal cultivado en invernadero unos 40.000.000 ptas/ha. En relación con los habituales problemas de escasez y suministro de agua para riego, y con la práctica de una agricultura de vanguardia con fórmulas de explotación intensivas, en todos los sectores de nuevas transformaciones en regadío de dichas comarcas - Campo del Bajo Segura (Riegos de la Pedrera), glacis meridionales de los relieves subbéticos de la Sierra de Crevillente-Pico del Agudo, y piedemontes de los relieves permotriásicos de la Sierras de Callosa y Orihuela-, abundan los regadíos dotados con sistemas de manejo de agua para riego de alta frecuencia, más específicamente la modalidad de riego por goteo, con unas 20.000 ha de las cuales más de la mitad se encuentran en el ámbito del Campo del Bajo Segura dependiendo del sistema de suministro del Postrasvase Tajo-Segura (Riegos de la Pedrera).

Inscritos en esas coordenadas deben interpretarse los efectos de daños de la última sequía que ha afligido estas tierras (vid. cuadros respectivos $n^{\circ} 8$ a 11), con un volumen de 
pérdidas económicas que supera, para el trienio 1992/94, según la valoración realizada por la Consellería de Agricultura 33.300 millones de pesetas en la provincia de Alicante; cifra que se eleva a 90.000 millones de pesetas, en todo el ámbito regado de la Cuenca del Segura según estimaciones del Sindicato Central de Regantes del Acueducto Tajo-Segura en las campañas 1992-93 y 1993-94.

Los factores que explican pérdidas tan ingentes en los cultivos de regadío pueden resumirse en:

- Reducción de superficies de cultivo en regadío: aunque con extensiones muy variables según el tipo de cultivo, la mayoría de producciones hortofrutícolas de las comarcas más afectadas citadas con anterioridad han experimentado hondos recortes en la extensión ocupada entre 1990 y 1994. La sequía 1992-94 ha venido a agravar los problemas de comercialización experimentados, en estos años, por diversas producciones. La grave situación ha alcanzado su grado máximo en el verano de 1994 donde la escasez de lluvias unido al golpe de calor de principios del mes de julio han provocado que numerosas hectáreas fundamentalmente de hortalizas — de gran valor comercial - y de ciertos cultivos industriales no hayan podido plantarse. Excepción a esta tónica ha sido, únicamente, el cultivo de girasol, ya que ha conocido una proparación inusitada al amparo de las subvenciones comunitarias que no exigen su recolección (cultivo protegido por la CEE). Como ejemplos de lo expresado baste señalar la honda disminución de superficie cultivada de alcachofa en la campaña de 1994 en relación a años anteriores, en las comarcas alicantinas del Bajo Vinalopó y Bajo Segura donde se ha pasado de 4.000 has cultivadas en 1990 a apenas 1.500 has en la última campaña. Como resultado de todo ello, lo cierto es que los precios alcanzados por la alcachofa en los mercados regionales en los inicios de la campaña 1994-1995 han supuesto hitos históricos, superándose las 400 ptas $/ \mathrm{kg}$.

- Menguas de producción y productividad: en relación con la disminución de superficie cultivada, la falta de dotaciones de agua para riego, la nula oportunidad de los pocos riegos aplicados, o la mediación de golpes de calor intensos como el ocurrido a principios de julio de 1994, la mayoría de producciones de regadío han sufrido recortes importantes (vid. cuadro $\mathrm{n}^{\circ} 8$ y 9 ). En las hortalizas, el referido ejemplo de la alcachofa ilustra la tónica general asimismo padecida en otras líneas de producción como el tomate, el pimiento, lechuga, melón, habas, patata, coliflor y bróculi, por citar las más representativas de la horticultura intensiva surestina, ya que la mayoría de ellas siquiera se han podido plantar por la falta de agua para riego.

- Junto a herbáceos o cultivos industriales (algodón), muy cuantiosas resultan las pérdidas en frutales. En efecto, y aunque solapada con la crisis de comercialización que sufren la mayor parte de líneas de producción frutícolas, la sequía ha provocado el abandono de numerosas plantaciones de frutales, destacando de manera particular las de limón, las cuales, al igual que otras parcelas de frutales, sólo han recibido dotaciones en torno a $1.000 \mathrm{~m}^{3} / \mathrm{ha}$ que, únicamente sirven para mantener, en precario estado de subsistencia, los árboles regados.

- Menguas de calidad: con mayor motivo, en producciones agrarias de regadío tan alejadas de sus óptimos ecológicos, las menguas de producción son acompañadas tambien con pérdidas de calidad tan importantes que hacen inviable su comercialización y acrecientan el nivel de perjuicios económicos. Así por ejemplo, en el pimiento cultivado en invernadero del municipio de Pilar de la Horadada, la insuficiencia de dotaciones del Trasvase Tajo-Segura no sólo ha incidido en una reducción notable de la superficie cultivada sino que además, su alto valor comercial ha hecho que los titulares de este tipo de explotaciones agrarias intensivas recurran a la 


\begin{tabular}{|c||c||c|}
\hline CULTIVOS & REDUCCION (\%) & $\begin{array}{c}\text { PRODUCCION NO } \\
\text { OBTENIDA (Tm) }\end{array}$ \\
\hline \hline CEREALES & -30.5 & 12.900 \\
\hline \hline TUBERCULOS & -16.5 & 10.600 \\
\hline \hline FORRAJEROS & -1 & 3.000 \\
\hline \hline ALGODON & -31.6 & 1.781 \\
\hline \hline LIMONERO & -4.2 & 10.900 \\
\hline ALMENDRO & -7 & 3.000 \\
\hline
\end{tabular}

Fuente: Consellería de Agricultura. Generalitat Valenciana.

Cuadro n. ${ }^{\circ} 9$

PÉRDIDAS DE COSECHA (Tm) EN 1993

POR REDUCCIÓN DE RENDIMIENTOS

\begin{tabular}{|c||c||c||c|}
\hline CULTIVOS & $\begin{array}{c}\text { PRODUCCION } \\
\text { MEDIA 1986/92 }\end{array}$ & PRODUCCION 1993 & $\begin{array}{c}\text { PERDIDA DE } \\
\text { COSECHA }\end{array}$ \\
\hline \hline HORTALIZAS & 176.750 & 157.034 & 19.716 \\
\hline NARANJO & 216.502 & 199.810 & 16.692 \\
\hline \hline MANDARINO & 21.532 & 21.442 & 90 \\
\hline \hline LIMINERO & 223.200 & 198.800 & 24.400 \\
\hline
\end{tabular}

Fuente: Consellería de Agricultura. Generalitat Valenciana.

Cuadro n..$^{\circ} 10$

COSECHA NO COMERCIALIZABLE (Tm) EN 1993

POR BAJOS CALIBRES

\begin{tabular}{|c||c||c||c|}
\hline CULTIVOS & $\begin{array}{c}\text { PRODUCCION EN } \\
\mathbf{1 9 9 3}\end{array}$ & $\begin{array}{c}\text { PORCENTAJE DE } \\
\text { BAJOS CALIBRES }\end{array}$ & $\begin{array}{c}\text { PRODUCCION NO } \\
\text { COMERCIALIZABLE }\end{array}$ \\
\hline \hline GRANADO & 21.000 & $20 \%$ & 4.200 \\
\hline \hline NARANJO & 199.810 & $20 \%$ & 39.962 \\
\hline \hline MANDARINO & 21.442 & $15 \%$ & 3.216 \\
\hline \hline LIMONERO & 198.800 & $15 \%$ & 29.820 \\
\hline
\end{tabular}

Fuente: Consellería de Agricultura. Generalitat Valenciana. 


\begin{tabular}{|c|c||c||c|}
\hline AÑO & $\begin{array}{c}\text { PERDIDAS } \\
\text { (Pts) }\end{array}$ & $\begin{array}{c}\text { PRODUCCION } \\
\text { FINAL } \\
\text { AGRARIA } \\
\text { (Pts) }\end{array}$ & $\begin{array}{c}\text { RELACION } \\
\text { ENTRE } \\
\text { PERDIDAS Y } \\
\text { P.F.A. }\end{array}$ \\
\hline \hline 1992 & 5.101 .000 .000 & 61.000 .000 .000 & $\mathbf{8} \%$ \\
\hline \hline 1993 & 8.259 .000 .000 & 60.000 .000 .000 & $\mathbf{1 3 \%}$ \\
\hline \hline 1994 & $\begin{array}{c}\text { por evaluar } \\
(20.000 .000 .000)\end{array}$ & -- & $\mathbf{3 0 \%}$ \\
\hline
\end{tabular}

\section{PRECIOS MAXIMOS PAGADOS EN BANCAL LIMON VERNA. 1993-1994.}

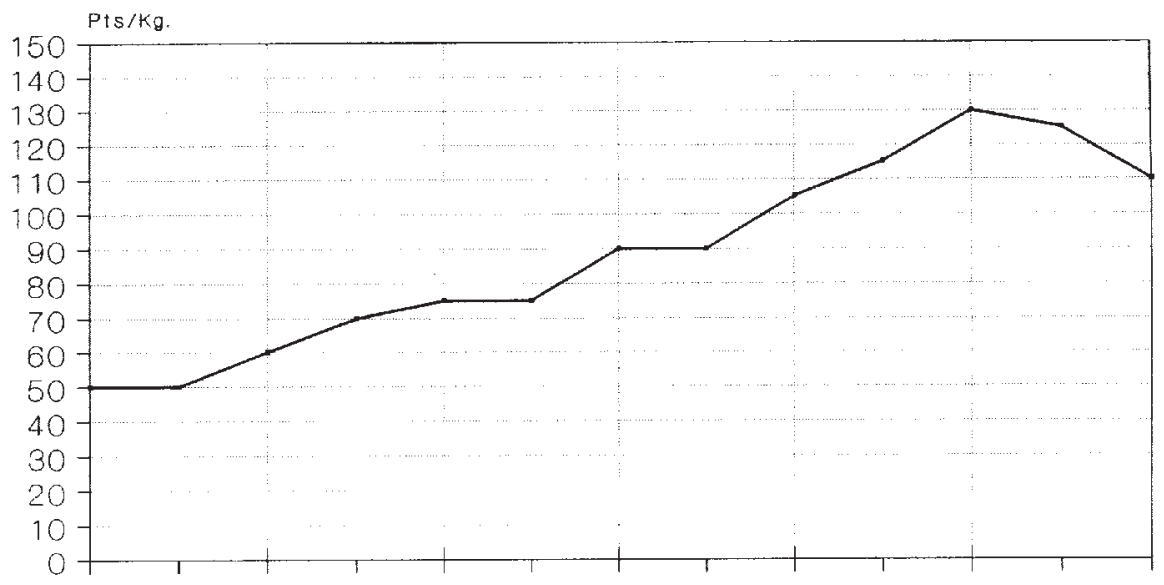

31-VIII-1993 25-IV-1994 4-VII-1994 18-VII-1994 1-VIII-1994 22-VIII-1994 12-IX-1994 - Pts/Kg

Fuente: Consellería de Agricultura.

Generalitat Valenciana 


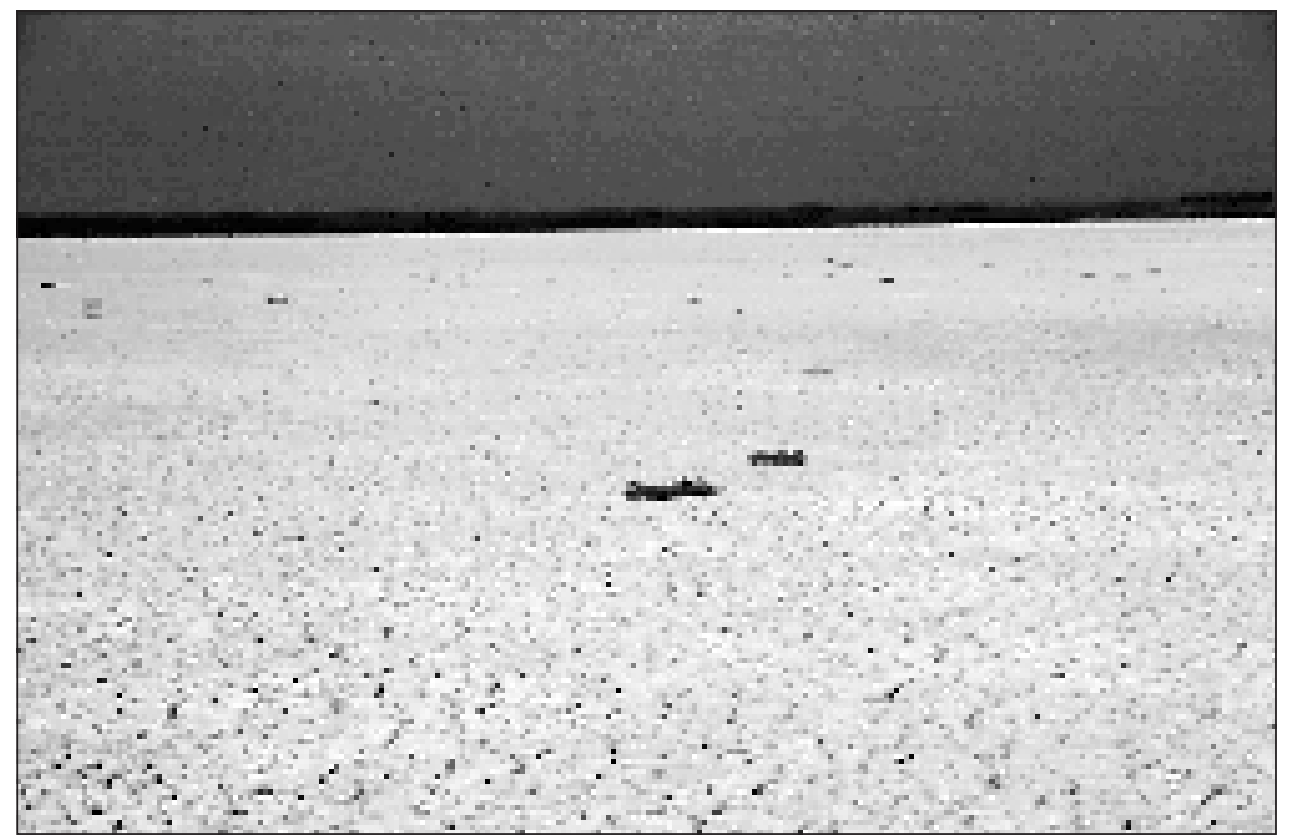

Fото No 2. Laguna del Hondo. Embalse de poniente completamente seco. Agosto 1994.

compra de aguas subterráneas con elevados contenidos salinos (por encima de $3.500 \mathrm{mmho} / \mathrm{cm}$ ). Estas aguas salobres ocasionan un aumento de la presión osmótica en la solución del suelo así como antagonismos entre nutrientes provocando una disminución del número y tamaño de los frutos y, con ello, la abundancia de calibres de menor valor comercial que reducen sobremanera la eficacia económica de la explotación. Asimismo, en cultivos arbóreos, el proceso es muy similar, sólo que en cultivos como el limón, por su menor valor comercial, los esfuerzos de sus propietarios por adquirir aguas subterráneas disminuyen y, con ello, aumenta el volumen de cosecha no comercializable por bajos calibres (vid. cuadro $\mathrm{n}^{\circ} 10$ ). Con esta situación agravada particularmente desde el verano de 1993, el porcentaje de cosecha de limón comercializable ha sido tan escaso que se ha revalorizado hasta extremos inusitados. Así los reducidísimos precios del limón Verna que regían en los mercados a principios de esta década (10-15 ptas $/ \mathrm{kg}$ ) han ascendido hasta los inverosímiles pagados en bancal en agosto de 1994 (130 ptas/kg.) (vid. gráfico $\left.n^{\circ} 8\right)$.

Difíciles de evaluar económicamente pero con un profundo calado en la opinión pública son los efectos que pueden ocasionar las secuencias de sequía en espacios naturales declarados de interés, como los humedales. Particularmente afectado resulta el paraje natural del Hondo al tratarse de una laguna artificial construida por el hombre (1932) que precisa, para su alimentación hídrica, de la elevación de caudales sobrantes del río Segura y de azarbes de avenamiento de la Vega Baja del Segura. Estas aguas, aunque de pésima calidad, permiten el desarrollo de un rico ecosistema de humedal en épocas de normalidad o abundancia de recursos hídricos. El problema se plantea cuando, en años de indigencia pluviométrica, la demanda de agua no puede ser satisfecha por falta de caudales sobrantes 


\begin{tabular}{|c||c||c||c|}
\hline COMARCA & CULTIVO & $\begin{array}{c}\text { PRODUCCION } \\
\text { PERDIDA } \\
\text { (Tm.) }\end{array}$ & $\begin{array}{c}\text { DAÑOS } \\
\text { EVALUADOS } \\
\text { (Pts) }\end{array}$ \\
\hline \hline $\begin{array}{c}\text { MEDIO } \\
\text { VINALOPO }\end{array}$ & $\begin{array}{c}\text { UVA DE MESA } \\
\text { (Italia) }\end{array}$ & 31.115 & 2.164 .000 .000 \\
\hline BAJO VINALOPO & $\begin{array}{c}\text { UVA DE MESA } \\
\text { (Italia) }\end{array}$ & 720 & 50.400 .000 \\
\hline \hline BAJO SEGURA & $\begin{array}{c}\text { UVA DE MESA } \\
\text { (Italia) }\end{array}$ & 750 & 52.500 .000 \\
\hline \hline MARINA ALTA & $\begin{array}{c}\text { UVA DE MESA } \\
\text { (Moscatel) }\end{array}$ & 181 & 7.300 .000 \\
\hline \hline
\end{tabular}

TOTAL

32.585

2.266 .900 .000

\begin{tabular}{|c||c||c|}
\hline ESPECIE & UNIDADES MUERTAS & $\begin{array}{c}\text { DAÑOS EVALUADOS } \\
\text { (Pts) }\end{array}$ \\
\hline \hline AVIAR & 34.048 & 4.108 .720 \\
\hline \hline CUNICOLA & 1.212 & 320.000 \\
\hline \hline PORCINO & 18 & 81.675 \\
\hline
\end{tabular}

TOTAL

4.510 .395

en el Segura, provocando un acusado descenso en el nivel del agua de los embalses que, incluso, como ha ocurrido en la temporada estival de 1994, ha culminado con la total desecación de los dos embalses (levante y poniente) que forman el humedal. Este hecho se ha saldado con la desaparición de peces (mujol y carpa) y avifauna (fochas, garzas). Los embalses se han convertido, en suma, en amplias extensión de terreno seco cubiertas por una costra salitrosa, progresivamente invadidas por especies vegetales de la clase Salicornietea (vid. foto $\mathrm{n}^{\circ} 2$ ). La Comunidad de Riegos de Levante ha aprovechado esta circunstancia para llevar a cabo una labor de dragado de los embalses a fin de mejorar la calidad de las aguas, cuando se restablezca la lámina de agua.

A diferencia de las secuencias de indigencia pluviométrica, los golpes de calor, cuando se presentan, van acompañados de daños generalizados aunque menos cuantiosos en todo 


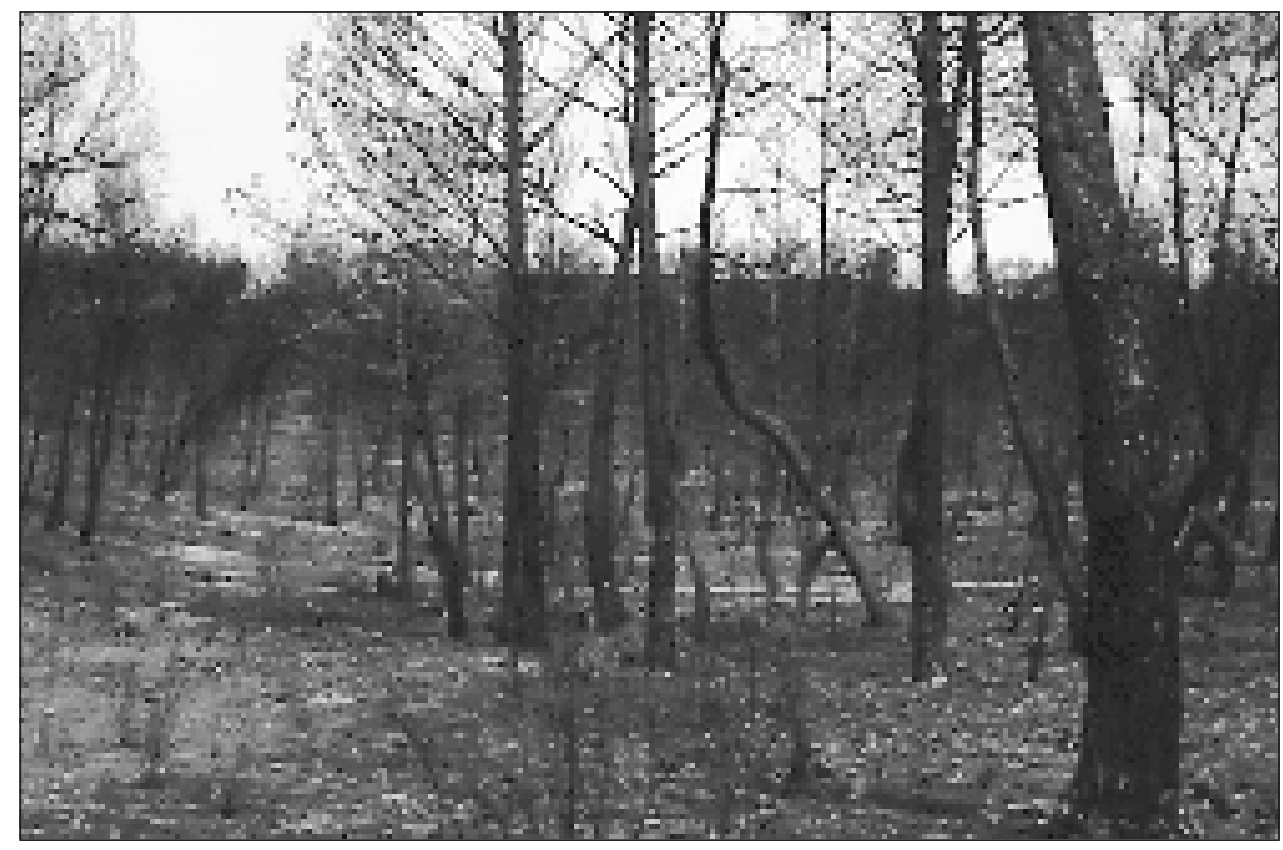

Fото No 3. Efectos del incendio en el monte Sotorroni (Alcoy) a consecuencia del golpe de calor de comienzos de julio de 1994.

el sureste ibérico, afectando a cultivos y a otros recursos naturales como la ganadería, montes (incendios forestales) y recursos cinegéticos. Así, los cultivos son incapaces de extraer del suelo toda el agua que precisan para restituir las pérdidas por evapotranspiración, y determinadas partes de la planta como son los frutos, por su elevado contenido en agua y por la escasa protección de sus paredes celulares, resultan literalmente quemados, o caso de encontrarse en período de floración como es habitual entre la mayor parte de hortalizas de verano, el trauma fisiológico que sufre la planta impide una adecuada polinización y fructificación. Entre las frutas más dañadas destaca la uva de mesa, sobre todo las variedades embolsadas destinadas a la exportación Aledo e Italia, en las cuales las altas temperaturas y la sequedad del aire sahariano asuran la totalidad del racimo embolsado; el cuadro $\mathrm{n}^{\circ} 12$, muestra las pérdidas económicas provocadas por el golpe de calor de los días 3 y 4 de julio de 1994 en las comarcas alicantinas del Vinalopó, Bajo Segura, y Marina Alta. La ganadería estabulada sufre, asimismo, importantes mermas cuando acontecen estos golpes de calor. Así, en las jornadas de calor ahornagante señaladas, resultaron muy dañadas las cabañas aviar y cunícola destacando, sobre todo, el número de cabezas muertas en la comarca del Bajo Segura (vid. cuadro n ${ }^{\circ} 12$ ).

Por último, estos golpes de calor aportan las condiciones propicias para la aparición y propagación de incendios forestales por el efecto desecante del aire sahariano que invade las tierras ibéricas. Así, ocurrió en las referidas fechas del 3 y 4 de julio, en las que a la superficies devastadas por el fuego en la comunidad catalana, acompañaron en el cuadrante sureste de la Península, los incendios de la Sierra de Moratalla en el Noroeste de Murcia, y en el Monte Sotorroni de Alcoy (vid. foto n 3). En la misma línea, aunque más difíciles de valorar económicamente, destacan los daños provocados en otro recurso natural como el 
cinegético. Los «golpes de calor» ocasionanon pérdidas irreparables en el conjunto de las especies cinegéticas, especialmente en la perdiz que no soporta jornadas continuadas de calor asfixiante, culminando con la muerte de perdigones y madres.

\section{CUADRO-RESUMEN \\ «SEQUÍAS Y GOLPES DE CALOR EN EL SURESTE IBÉRICO»}

\begin{tabular}{|c|c|c|}
\hline & GOLPES DE CALOR & $\begin{array}{r}\text { SEQUIAS } \\
\end{array}$ \\
\hline $\begin{array}{c}\text { ASPECTOS } \\
\text { ATMOSFERICOS }\end{array}$ & $\begin{array}{l}\text {-Episodio de corta duración (1-3 } \\
\text { dias) } \\
\text {-Tipología sinóptica asociada a la } \\
\text { presencia de masas de aire } \\
\text { subtropicales (crestas saharianas y } \\
\text { dorsales) o circulaciones zonales } \\
\text { (ponent) } \\
\text {-Registros térmicos máximos } \\
\text { absolutos } \\
\text {-Ausencia de precipitaciones }\end{array}$ & $\begin{array}{l}\text {-Distinción entre año seco } \\
\text { (precipitaciones inferiores al 60\% de } \\
\text { la media anual durante } 12 \text { meses) y } \\
\text { secuencia de indigencia pluviométrica } \\
\text { (precipitaciones inferiores al } 60 \% \text { de } \\
\text { la media anual en un período nunca } \\
\text { inferior a } 16 \text { meses). } \\
\text {-Reducción aguda de lluvias y, por } \\
\text { tanto, modificación del régimen } \\
\text { pluviométrico mediterráneo propio de } \\
\text { estas tierras. } \\
\text {-Tipología sinóptica asociada a la } \\
\text { presencia frecuente de masas de aire } \\
\text { subtropicales (crestas saharianas y } \\
\text { dorsales) o circulaciones zonales } \\
\text { (ponent). }\end{array}$ \\
\hline $\begin{array}{c}\text { EFECTOS } \\
\text { ECONOMICOS }\end{array}$ & $\begin{array}{l}\text {-Asurado de las producciones } \\
\text { agricolas: particularmente afectadas } \\
\text { las producciones de uva de vino y } \\
\text { mesa (quema de raspa y grano). } \\
\text {-Problemas de asfixia en granjas } \\
\text { avícolas. } \\
\text {-Incremento de precios de mercado } \\
\text { en producciones agrarias por } \\
\text { reducción de oferta (limón verna, } \\
\text { olivo, alcachofa) }\end{array}$ & $\begin{array}{l}\text { - Aumento de "barbechos forzados" } \\
\text {-Reducción de superficie dedicada a } \\
\text { hortalizas } \\
\text {-Problemas de comercialización por } \\
\text { aumento de bajos calibres } \\
\text {-Incremento de precios en } \\
\text { producciones agrarias por falta de } \\
\text { oferta (aceituna) } \\
\text {-Incremento del precio del agua } \\
\text { subterránea. } \\
\text {-Reducción de dotaciones de agua por } \\
\text { hectárea }\end{array}$ \\
\hline $\begin{array}{c}\text { EFECTOS } \\
\text { MEDIO- } \\
\text { AMBENTALES }\end{array}$ & $\begin{array}{l}\text {-Situación propicia para la } \\
\text { propagación de incendios forestales. }\end{array}$ & $\begin{array}{l}\text {-Problemas de sobreexplotación de } \\
\text { aguas subterráneas: salinización de } \\
\text { acuíferos. } \\
\text {-Problemas de abastecimiento de agua } \\
\text { para consumo humano en núcleos de } \\
\text { población no mancomunados } \\
\text { (Montaña de Alicante) } \\
\text {-Sequedad ambiental propicia para el } \\
\text { desarrollo de incendios forestales. } \\
\text {-Efectos perniciosos sobre espacios } \\
\text { naturales anfibios (humedales) }\end{array}$ \\
\hline
\end{tabular}




\section{Bibliografía}

GIL OLCINA, A.: La propiedad de aguas perennes en el Sureste Ibérico. Universidad de Alicante, 1993, $191 \mathrm{pp}$.

GIL OLCINA, A.: «Desequilibrio de recursos hídricos y planteamiento de trasvases en territorio valenciano» en Coloquio sobre Planificación Hidráulica en España. Instituto Universitario de Geografía. Universidad de Alicante y Fundación Cultural CAM., Alicante, noviembre 1994.

INSTITUTO TECNOLÓGICO GEOMINERO DE ESPAÑA: Anuario Los Peligros Naturales (años 1991 y 1992). Madrid, 1992 y 1994.

MORAlES GIL, A. y VERA REBOllo, J. F.: La Mancomunidad de los Canales del Taibilla. Instituto Universitario de Geografía. Universidad de Alicante y Academia Alfonso X El Sabio. Alicante, 1989, 133 pp.

MORALES GIL, A.: «Déficit de agua y demanda de transferencias en la Cuenca del Segura» en Coloquio sobre Planificación Hidráulica en España. Instituto Universitario de Geografía. Universidad de Alicante y Fundación Cultural CAM, Alicante, noviembre 1994.

OLCINA CANTOS, J.: Episodios meteorológicos de consecuencias catastróficas en las tierras alicantinas, 1900-1990. (Tesis doctoral, inédita). Instituto Universitario de Geografía. Universidad de Alicante. Alicante, 1993, 1.549 pp.

RICO AMORÓS, A.: Sobreexplotación de aguas subterráneas y cambios agrarios en el Alto y Medio Vinalopó. Instituto Universitario de Geografía de la Universidad de Alicante e Instituto de Cultura Juan Gil-Albert. Alicante, 1994, 250 pp.

VALERO AMAT, P.: Olas de calor y altas temperaturas en tierras alicantinas. (Memoria de Licenciatura, inédita). Instituto Universitario de Geografía. Universidad de Alicante. Alicante, $1991,1.283$ pp.

VV.AA. Jornadas sobre las sequías en España. Real Academia de Ciencias Exactas, Físicas y Naturales. Madrid, noviembre de 1990, 475 pp.

ZAPATA NICOLÁS, M. et alii.: Repercusiones económicas de la sequía 1980-1983 en el sector agrario de la cuenca del Segura. C.S.I.C., Murcia, 1990, 237 pp. 